\title{
Effects of Precast Cladding Systems on Dynamic Characteristics of Steel Frame Buildings by Ambient and Free Vibration Tests
}

\author{
Jun Ma, ${ }^{1}$ Shinji Nakata, ${ }^{2}$ Akihito Yoshida, ${ }^{3}$ and Yukio Tamura ${ }^{4}$ \\ ${ }^{1}$ College of Civil Engineering, Tongji University, Shanghai, China \\ ${ }^{2}$ Asahi Kasei Homes Corporation Co., Ltd., Shizuoka, Japan \\ ${ }^{3}$ School of Architecture and Wind Engineering, Tokyo Polytechnic University, Atsugi, Japan \\ ${ }^{4}$ School of Civil Engineering, Beijing Jiaotong University, Beijing, China
}

Correspondence should be addressed to Jun Ma; 1010020011@tongji.edu.cn

Received 16 February 2017; Accepted 29 March 2017; Published 13 April 2017

Academic Editor: Guillermo Rus

Copyright (c) 2017 Jun Ma et al. This is an open access article distributed under the Creative Commons Attribution License, which permits unrestricted use, distribution, and reproduction in any medium, provided the original work is properly cited.

\begin{abstract}
Full-scale tests on a one-story steel frame structure with a typical precast cladding system using ambient and free vibration methods are described in detail. The cladding system is primarily composed of ALC (Autoclaved Lightweight Concrete) external wall cladding panels, gypsum plasterboard interior linings, and window glazing systems. Ten test cases including the bare steel frame and the steel frame with addition of different parts of the precast cladding system are prepared for detailed investigations. The amplitude-dependent dynamic characteristics of the test cases including natural frequencies and damping ratios determined from the tests are presented. The effects of the ALC external wall cladding panels, the gypsum plasterboard interior linings, and the window glazing systems on the stiffness and structural damping of the steel frame are discussed in detail. The effect of the precast cladding systems on the amplitude dependency of the dynamic characteristics and the tendencies of the dynamic parameters with respect to the structural response amplitude are investigated over a wide range. Furthermore, results estimated from the ambient vibration method are compared with those from the free vibration tests to evaluate the feasibility of the ambient vibration method.
\end{abstract}

\section{Introduction}

Steel frames with precast cladding systems are very commonly used in both residential and office construction in many parts of the world including North America, Europe, and Japan. According to current design codes, steel frames are required to resist lateral and vertical loads under ultimate and serviceability loading conditions, while precast cladding systems are considered as non-load-bearing components considering only their mass and hence are ignored in the structural design. However, experimental investigations and analytical studies have demonstrated that precast cladding systems can in fact have a significant impact on the stiffness and dynamic response of steel frames. The addition of precast cladding systems to an originally bare moment-resisting steel frame may enhance both the lateral stiffness and strength of the steel frames and alter the dynamic response of the overall structural system [1-7]. Precast cladding systems do in fact interact with steel frames and alter their intended performance.

Dynamic behavior is one of the most important design considerations for buildings, and dynamic responses of steel frame buildings under wind- or earthquake-induced loadings are strongly dependent on dynamic parameters such as natural frequencies, damping ratios, and mode shapes. Several experimental studies have shown that precast cladding systems can affect the dynamic characteristics of steel frames. They can cause stiffening of steel frame structures and result in an increase in natural frequencies [8-10]. Interaction between precast cladding systems and steel frames can lead to friction at the interfaces between primary structural members and secondary components and result in an increase in damping ratios [11, 12]. However, in current design practice, the effect of precast cladding systems is often neglected because of lack of knowledge of the complex interaction between them and steel frames. As a 
result, computed dynamic responses based on the bare frame model may be quite different from those actually experienced by the clad steel frame.

Moreover, from field measurements made over the last three decades, it has been recognized that natural frequencies and damping ratios are nonlinear parameters and may increase with vibration amplitude [13-15]. However, in structural design, natural frequencies and damping ratios are usually assumed to be constant and independent of structural response magnitudes, and the limited number of studies of dynamic response analysis of buildings considering amplitude-dependent dynamic characteristics has shown that the current design assumption does not appear to be conservative [16]. An understanding of the precise nature of amplitude-dependent dynamic characteristics is of utmost importance in design of steel frame buildings subject to dynamic lateral loads.

This paper investigates the effects of a precast cladding system on the dynamic characteristics of a full-scale onestory moment-resisting steel frame and studies the amplitude dependency of dynamic characteristics. The precast cladding system considered in this paper mainly consists of ALC (Autoclaved Lightweight Concrete) external wall cladding panels, gypsum plasterboard interior linings, and corresponding window glazing systems. Ambient vibration tests (AVT) and free vibration tests (FVT) were conducted on the steel frame to provide a basis for evaluation of dynamic characteristics, and corresponding output-only system identification algorithms were applied to field acceleration measurements to estimate those dynamic parameters with respect to response amplitude. The outcome of this study is expected to promote understanding of the effects of precast cladding systems on the evaluation of dynamic parameters of steel frame buildings and on the amplitude dependency of dynamic characteristics and to evaluate the adequacy of current design practices.

\section{Experimental Works}

2.1. Description of Steel Frame and Precast Cladding System. A full-scale one-story one-bay steel frame with a precast cladding system was designed and fabricated, and ambient vibration and free vibration tests were conducted.

The steel frame was designed as one section of an actual low-rise residential house. Figure 1 shows plans and elevations. The steel frame was $3050 \times 3050 \mathrm{~mm}$ in plan and $3120 \mathrm{~mm}$ high. The four corner columns, marked C1, were box sections $150 \times 150 \times 9 \mathrm{~mm}$ thick, and all the beams, marked G1 in the first and second floors, were $\mathrm{H}$ sections $250 \times 125 \times 4.5$ $\times 9 \mathrm{~mm}$ thick. The yield strength of all the columns and beams was $235 \mathrm{Mpa}$. Sixteen steel plates were set on the second floor to simulate real surface loads. Their dimensions were 1210 $\times 905 \times 55 \mathrm{~mm}$ thick and they each weighted $4.64 \mathrm{KN}$. In order to support them, two steel beam layers were fixed on the second floor. The lower layer consisted of $\mathrm{H}$-section beams $250 \times 125 \times 4.5 \times 9 \mathrm{~mm}$ thick, and the upper layer consisted of $\mathrm{H}$-section beams $125 \times 125 \times 6.5 \times 9 \mathrm{~mm}$ thick.

The precast cladding system was designed and fabricated following conventional construction procedures. ALC external wall cladding panels, gypsum plasterboard interior linings, and window glazing systems were installed symmetrically on the steel frame. These cladding components are detailed in Table 1. The ALC external wall cladding panels were fixed onto the steel frame using the "Rocking Installation System" method, and the ALC panels were connected to the beams at the top and bottom to permit rocking in case of earthquakes [17]. Figure 2 illustrates the typical "Rocking Installation Method" between ALC claddings and the steel frame. Each external wall comprised three vertically installed general ALC panels and two corner ALC panels, and the gaps between panels were filled with silicone sealing compound. Plasterboard $12.5 \mathrm{~mm}$ thick was used as the lining material and was attached to the internal face of the ALC external wall claddings through wood stud framings. Three window glazing systems were also considered in this study.

In order to investigate the effects of the precast cladding system in detail, ten cases were tested, and the effects of the ALC cladding panels, plasterboard, and window glazing systems were investigated in detail and separately. The test cases are summarized in Table 2, and the layout of each case is shown in Figure 3. In order to speed up the testing process, two test cases were assembled in the steel frame simultaneously, one along $X$ direction and the other along $Y$ direction. As the free vibration tests conducted are made in one direction per step, each case is made independently but two cases are tested on the same structure. Figure 4 shows external views of Case 2 and Case 4, in which ALC claddings and small windows were installed in the steel frame. Figure 5 shows external views of Case 6 and Case 8, in which middle windows and large windows were installed. Figure 6 shows internal view of Case 7, in which plasterboard was installed as interior lining. Figure 7 shows the external view of Case 10, in which two ALC layers were installed along $X$ direction.

2.2. Testing Procedure and Instrumentation. Ambient vibration and free vibration tests were conducted to estimate corresponding natural frequencies and damping ratios for each test case. Ambient vibration tests were adopted due to their advantages of being economical and practical, and experience with this testing procedure has shown its validity $[15,18,19]$. In the current study, ambient vibration tests were carried out in the laboratory using microtremors, and the response magnitudes to ambient excitation were low. An ambient vibration test was conducted before each free vibration test, and the duration of the ambient vibration test was 60 minutes.

Free vibration tests were conducted after each ambient vibration test. The free vibration test is a common and simple method for identifying dynamic characteristics, and it is known to be a reliable excitation method to provide accurate mode parameters. In the current study, the free vibration tests were carried out using an electromagnetic shaker. The shaker was placed at the center of the second floor, and its excitation orientation was kept along with the direction of each case. The setup of the shaker was illustrated in Figure 1. The shaker was used so that it excited each case at its fundamental natural frequency at first and then suddenly stopped to allow the "free vibration" to occur. Free vibration tests were 

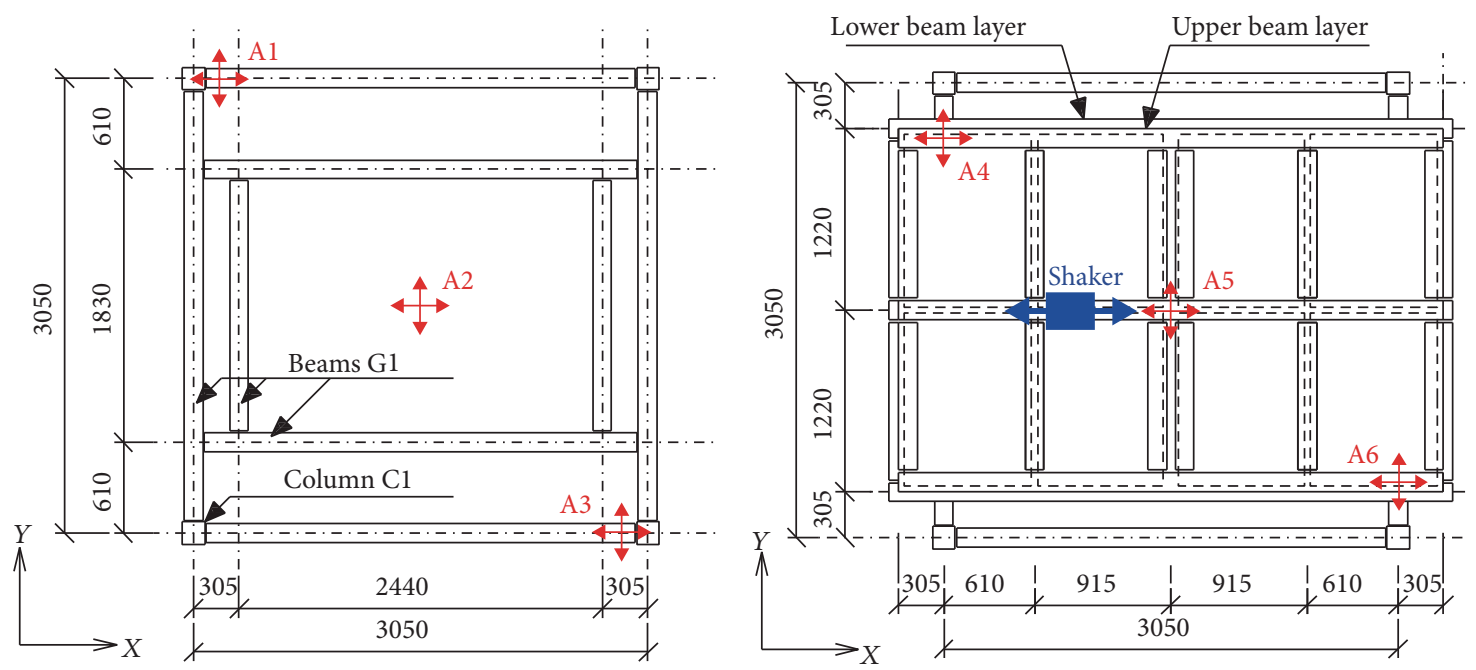

Notes

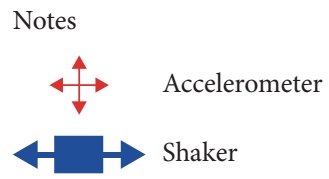

(a) Plan of $1 \mathrm{~F}$

(b) Plan of $2 \mathrm{~F}$
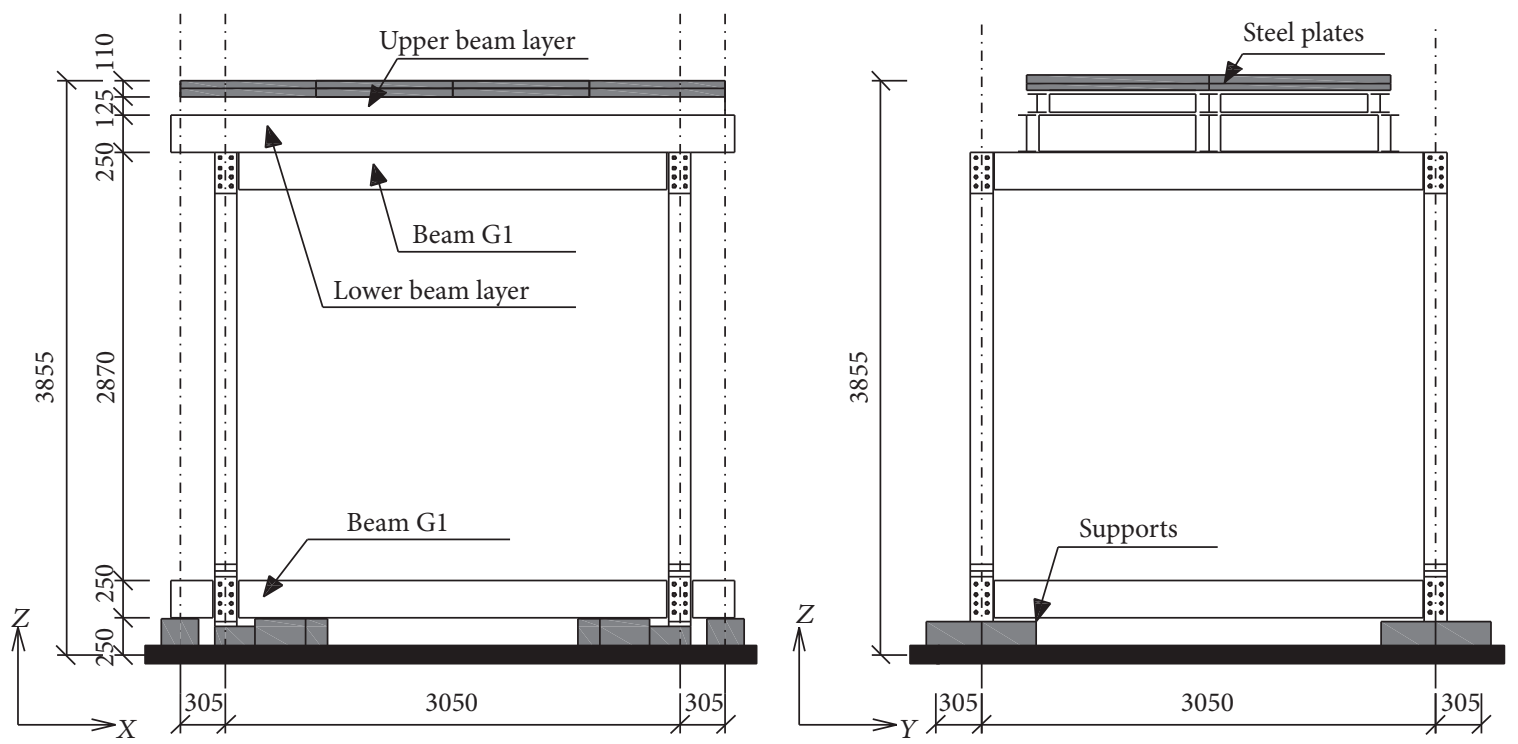

(c) Elevation in $X$ direction

(d) Elevation in $Y$ direction

FIGURE 1: Plans and elevations of steel frame (unit: $\mathrm{mm}$ ).

TABLE 1: Details of precast cladding components.

\begin{tabular}{|c|c|c|c|}
\hline \multicolumn{2}{|c|}{ Cladding components } & Dimensions & Weight \\
\hline \multicolumn{2}{|c|}{ ALC external wall cladding panels } & $2130 \times 2870 \times 75 \mathrm{~mm}$ thick & $0.49 \mathrm{KN} / \mathrm{m}^{2}$ \\
\hline \multicolumn{2}{|c|}{ Plasterboard interior linings } & $1830 \times 2620 \times 12.5 \mathrm{~mm}$ thick & $0.20 \mathrm{KN} / \mathrm{m}^{2}$ \\
\hline \multirow{3}{*}{ Window openings } & Small size & $610 \times 460 \mathrm{~mm}$ & - \\
\hline & Middle size & $610 \times 1420 \mathrm{~mm}$ & - \\
\hline & Large size & $1830 \times 1420 \mathrm{~mm}$ & - \\
\hline
\end{tabular}


TABLE 2: Summary of test cases.

\begin{tabular}{lcc}
\hline Case number & Construction characteristics & Direction \\
\hline 1 & Bare steel frame & $X$ \\
2 & Steel frame + ALC claddings & $Y$ \\
3 & Steel frame + ALC claddings + plasterboard & $Y$ \\
4 & Steel frame + ALC claddings + small window & $X$ \\
5 & Steel frame + ALC claddings + plasterboard + small window & $X$ \\
6 & Steel frame + ALC claddings + middle window & $Y$ \\
7 & Steel frame + ALC claddings + plasterboard + middle window & $Y$ \\
8 & Steel frame + ALC claddings + large window & $X$ \\
9 & Steel frame + ALC claddings + plasterboard + large window & $X$ \\
10 & Steel frame + ALC claddings composed of two layers & \\
\hline
\end{tabular}

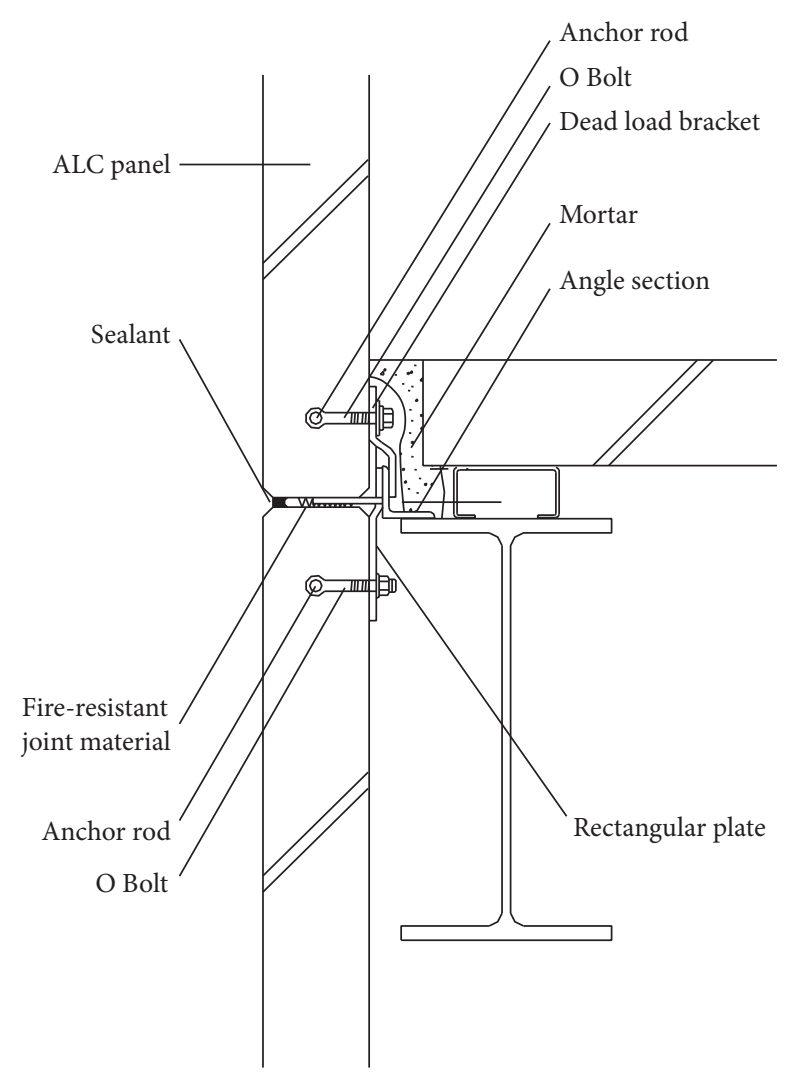

FIgURE 2: A typical "Rocking Installation Method”.

repeated three times for each case in order to obtain more data and reduce errors, and each acceleration amplitude was made independently. Natural frequencies and damping ratios were estimated from each test data and then were averaged. The estimated natural frequencies and damping ratios were derived in an amplitude range that was wider than that of the ambient vibration tests.

Six servo-type accelerometers, marked A1 to A6, were utilized to collect the response acceleration data. Their layout was illustrated in Figure 1. A1 to A3 were located on the first floor, and A4 to A6 were located on the top floor. On each floor, one accelerometer was located at the center and the other two were located at two diagonally opposite corners.
Each servo-type accelerometer could record response acceleration data at a rate of 100 samples per second in the $X$ and $Y$ directions simultaneously.

\section{Processing of Ambient Vibration Test Data and Results}

3.1. Description of Applied Mode Identification Method. In ambient vibration tests, only output data can be measured and recorded, while there is no way to obtain input information. Thus, characteristic dynamic parameters can only be identified from output data using output-only modal identification techniques. In the past several decades, outputonly modal identification techniques have developed fast and there are already a lot of output-only modal identification techniques available. Moreover, several output-only mode identification methods have succeeded in estimating dynamic parameters from ambient vibration tests, like frequency domain decomposition (FDD), Random Decrement Technique (RDT), stochastic subspace identification (SSI), eigensystem realization algorithm (ERA), and so forth [15, 19-21].

As mentioned in the Introduction, dynamic characteristic parameters are nonlinear with respect to response magnitudes. In order to estimate amplitude-dependent parameters, the Random Decrement Technique was adopted in this study to process ambient vibration test data. The Random Decrement Technique is a powerful method for estimating amplitude-dependent dynamic characteristics and some researchers have succeeded in using it to identify amplitudedependent dynamic parameters for full-scale structures [15, $16,22]$. The principle of RDT is based on the assumption that the dynamic response of a structure is composed of a deterministic part and a random part. With a given trigger value, the dynamic response can be decomposed into a series of time segments with equal time length $\tau$ in the time interval $\left[t_{i}, t_{i+\tau}\right](i=1,2, \ldots, 2 n)$. By taking the average of a large number of time segments, the random part in the dynamic response tends to zero, leaving only the deterministic part, which is called the $\mathrm{RD}$ function and represents a free vibration signal of the structure caused by the trigger value. The natural frequency and damping ratio with respect to the trigger value can be estimated from the RD function by using 

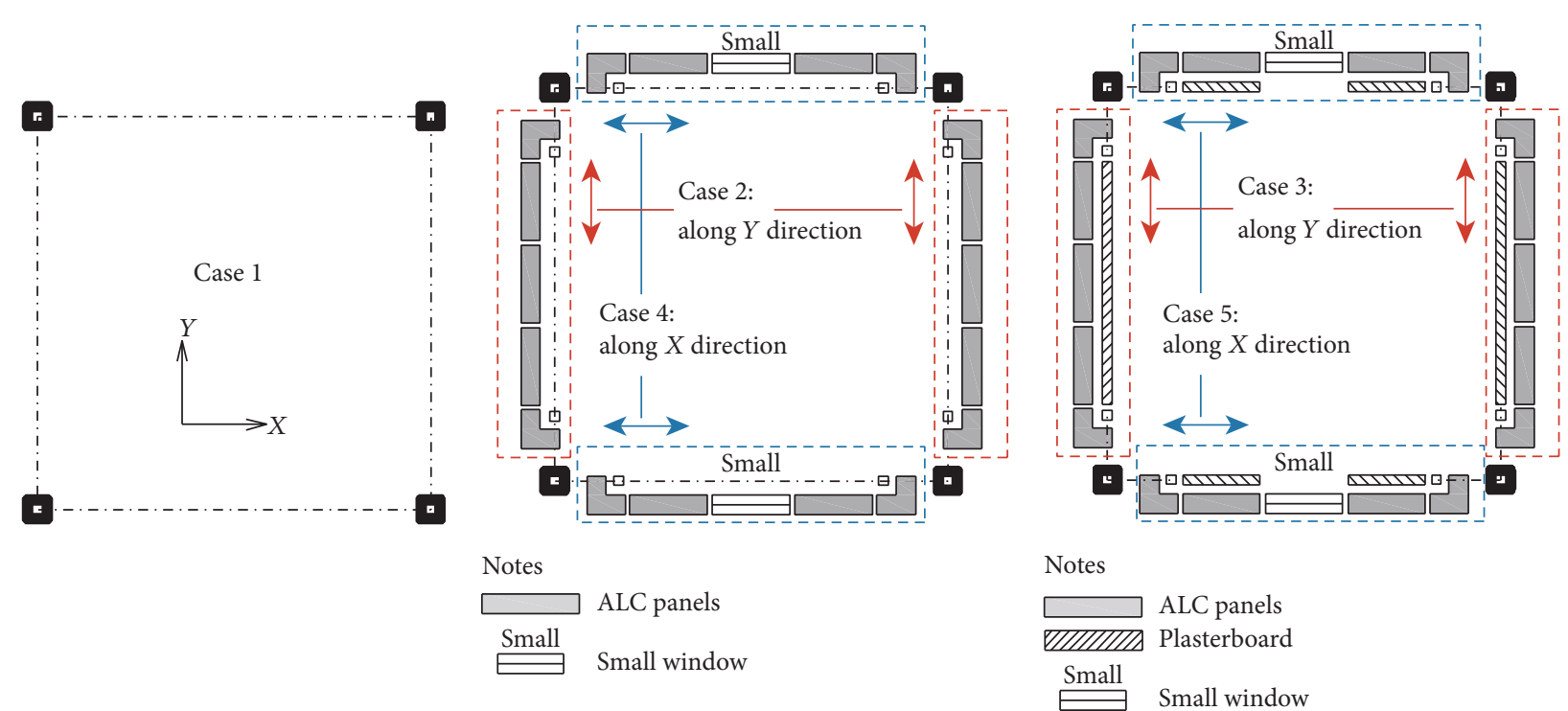

(a) Case 1

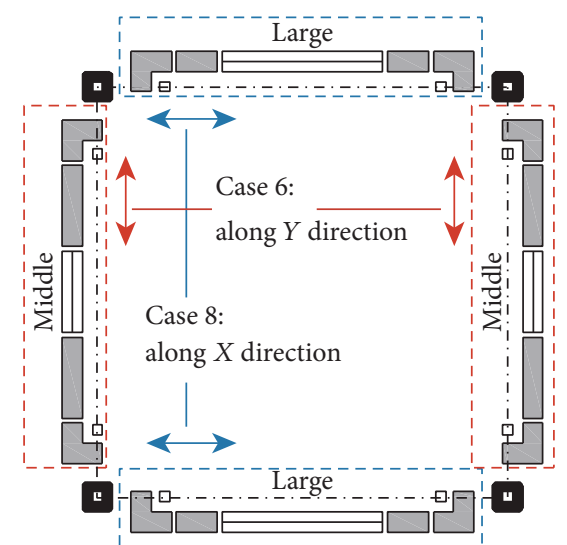

Notes

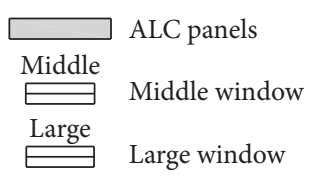

(d) Case 6 and Case 8 (b) Case 2 and Case 4
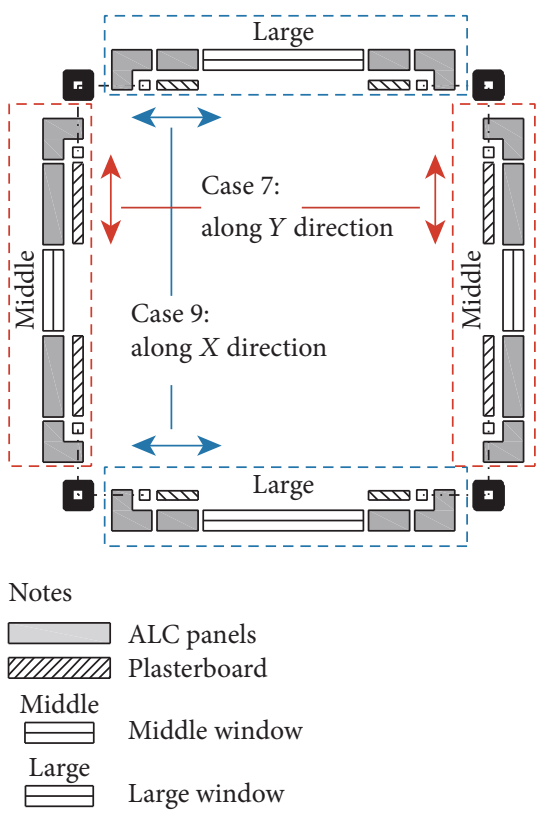

(e) Case 7 and Case 9 (c) Case 3 and Case 5

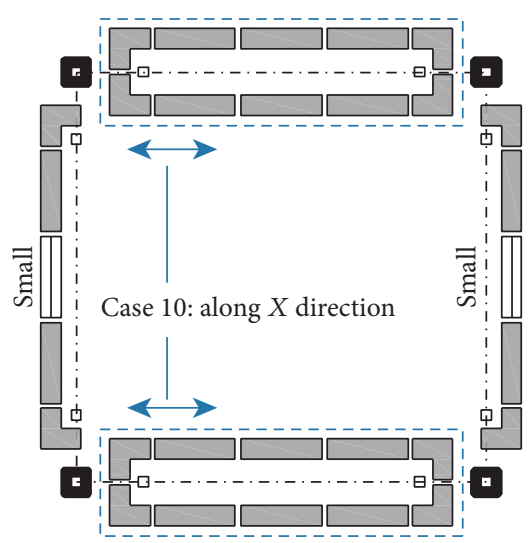

Notes

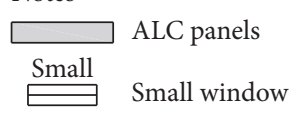

(f) Case 10

Figure 3: Layout of test cases.

algorithms developed to extract modal parameters from free decay functions, like the Logarithmic Decrement Technique (LDT), the Curve Fitting Technique (CFT), and so forth. The $\mathrm{RD}$ function extracted from the dynamic response can be expressed as

$$
z(\tau, c)=\frac{1}{2 N} \sum_{i=1}^{2 N} \operatorname{sgn}\left[y\left(t_{i}+\tau, c\right)\right] \cdot y\left(t_{i}+\tau, c\right),
$$

where $y(t, c)$ is the displacement, velocity, or acceleration response at time $t$ with the trigger value of $c, \operatorname{sgn}[y(t, c)]$ is the signum function of $y(t, c), t_{i}$ is the $i$ th time instant corresponding to the trigger value, and $2 \mathrm{~N}$ is the number of time segments.

RDT allows an estimation of amplitude-dependent dynamic parameters. With a set of gradually increasing trigger values in the range of structure response, a set of $\mathrm{RD}$ functions can be extracted from the dynamic response and corresponding dynamic characteristic parameters can be evaluated. Thus, the relationship between dynamic characteristic parameters and trigger values, which is physically the structure response amplitude, can be established. The procedure of processing ambient vibration test data is described in Section 3.2. 


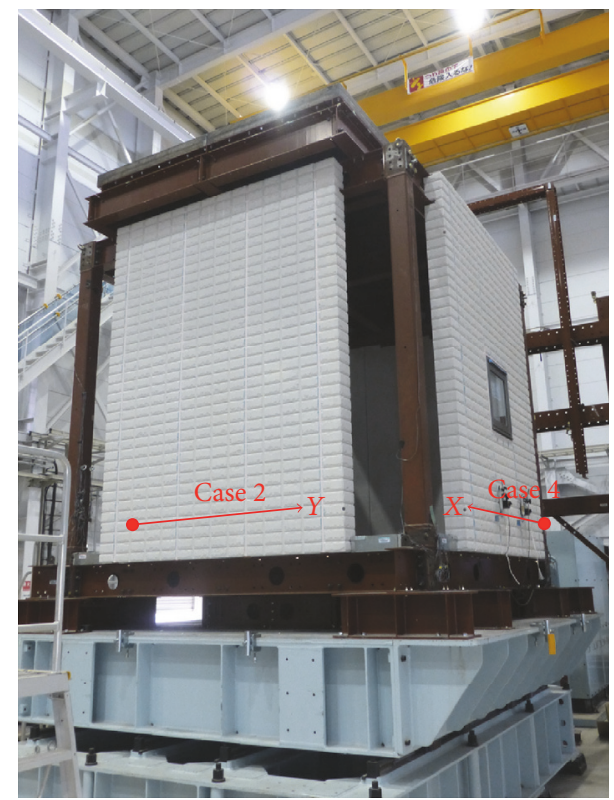

Figure 4: External views of Case 2 and Case 4.

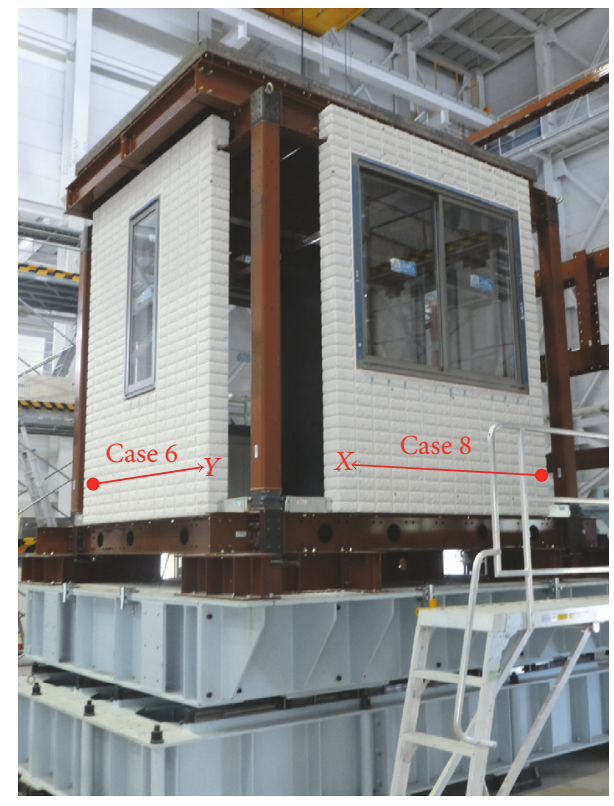

Figure 5: External views of Case 6 and Case 8.

3.2. Data Processing Procedure. During the processing procedure, ambient vibration test data first passes through a bandpass filter to isolate the contribution of the target mode. Then, $\mathrm{RDT}$ is applied to extract RD functions. Finally, natural frequencies and damping ratios with respect to corresponding trigger values are evaluated from free decay functions using the Curve Fitting Technique. The processing procedure is described in the following steps.

(1) The response acceleration data is transformed into the frequency domain using Fourier transformation and then passes through a bass-pass filter to isolate

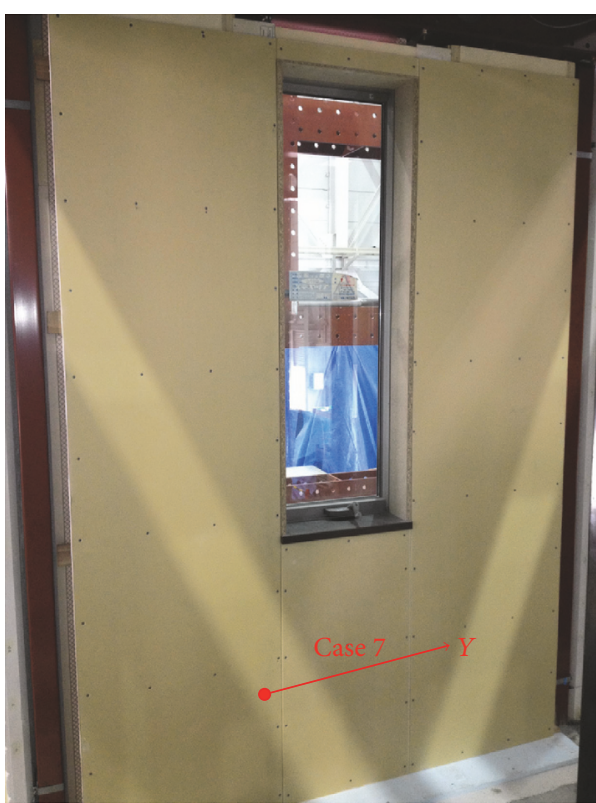

FIGURE 6: Internal view of Case 7.

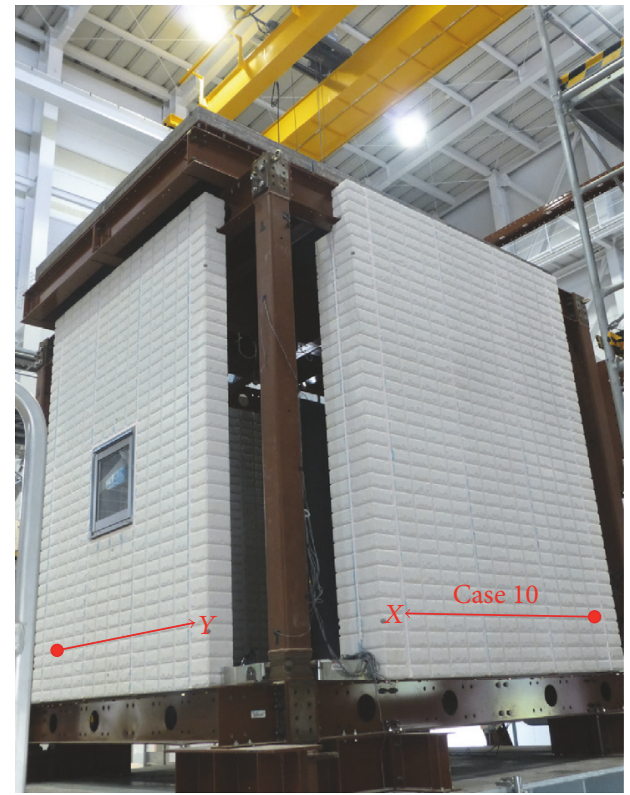

Figure 7: External view of Case 10.

the contribution of the target mode. Afterwards, the filtered acceleration time-history data containing the target modal information is derived from inverse Fourier transformation. An appropriate band-pass filter is required in this step, in which the bandpass filter should not be too wide or too narrow. The band-pass filter's width is determined using a successive approximation approach that the bandpass filter's width increases gradually in the vicinity of the target natural frequency until the estimated natural frequency or damping ratio stays stable with increasing width. 


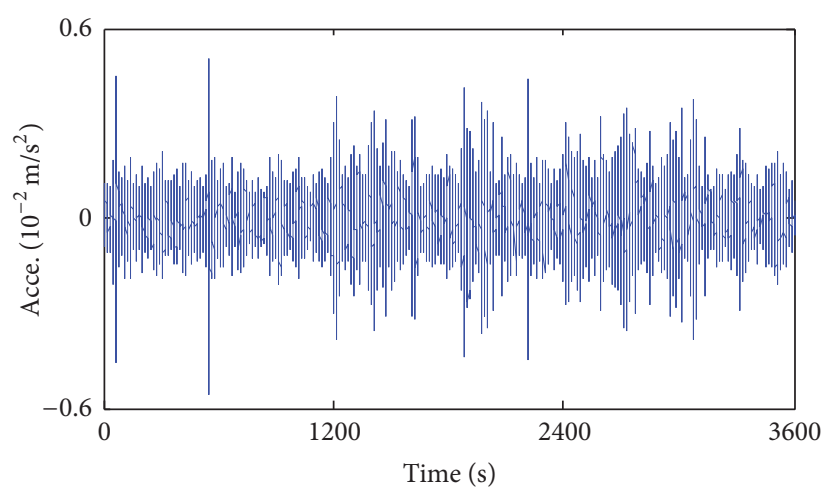

(a) Time history of response acceleration data on top floor

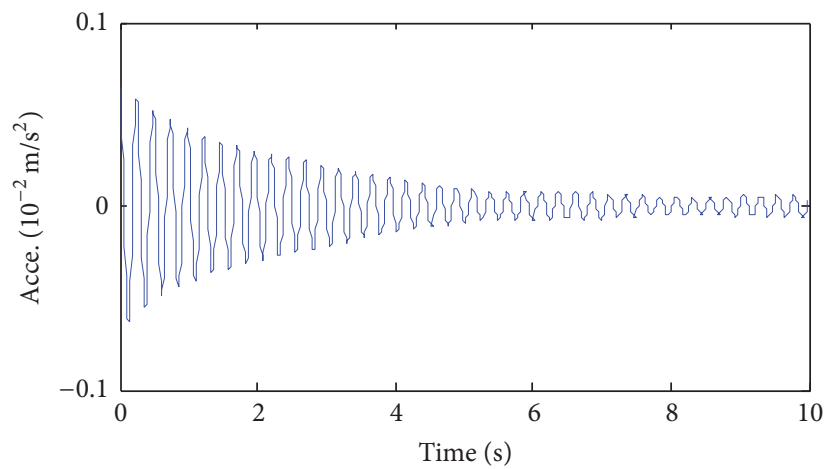

(c) RD function

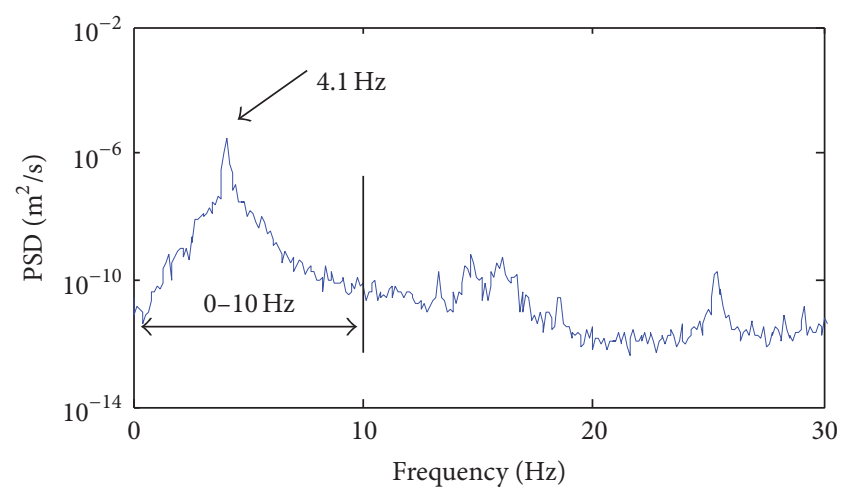

(b) Fourier spectrum of response acceleration data

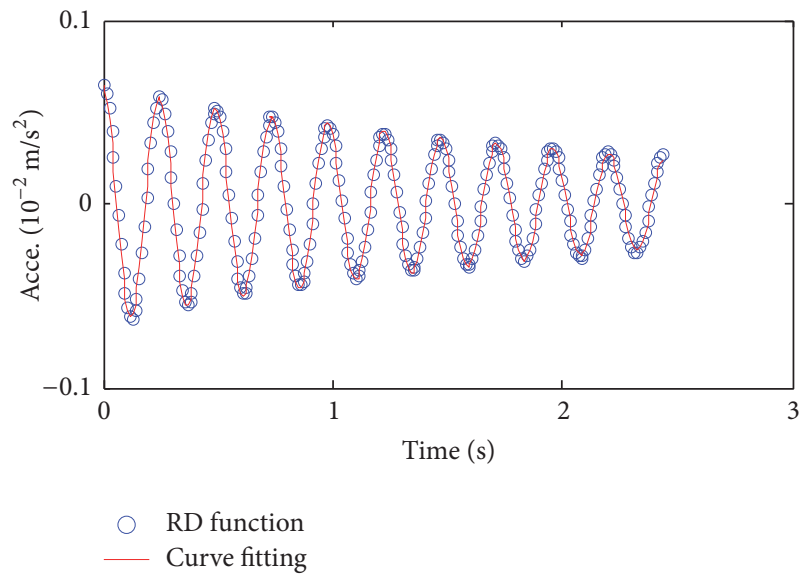

(d) Curving fitting result

FIGURE 8: Data processing procedure of ambient vibration test data of Case 3.

(2) $\mathrm{RD}$ functions corresponding to the prescribed trigger values are extracted from the filtered acceleration data using RDT. Appropriate trigger values and time segment length are two important parameters, because these two parameters determine the number of time segments and the quality of the RD functions. Trigger values can be checked according to RD functions, so that a trigger value should be denied if its corresponding $\mathrm{RD}$ function does not well represent the free decay function. Time segment length can be determined such that the relationship between segment length and natural frequency or damping ratio is established first and then the segment length is selected in the range in which natural frequency or damping ratio stays stable. Although high amplitude and long free decay records are anticipated, it should be noted that a high trigger value and a long segment length will lead to an insufficient number of time segments and induce low quality RD functions.

(3) The Curve Fitting Technique is adopted to evaluate natural frequencies and damping ratios from $\mathrm{RD}$ functions. The first ten cycles of each RD function are fitted with the theoretical formula of the free decay function, and corresponding natural frequency and damping ratio are identified. The error ratio between
$\mathrm{RD}$ function and fitting result is restricted to less than $3 \%$. The theoretical formula for the free decay function is written as

$$
x(t)=x_{0} e^{-\omega_{n} \zeta t} \cos \left(\sqrt{1-\zeta^{2}} \omega_{n} t\right),
$$

where $x_{0}$ is the amplitude determined by the initial condition or trigger values in the current study; $\omega_{n}$ is natural circular frequency and $\zeta$ is damping ratio.

Figure 8 illustrates the application of the processing procedure suggested above to the ambient vibration test data of Case 3, and the response acceleration data at the top/center of the roof was employed. The time history of the response acceleration data and the corresponding Fourier spectrum are shown in Figures 8(a) and 8(b), respectively. A bandpass filter with the width shown in Figure 8(b) was applied to extract the contribution of the fundamental mode. The natural frequency of the fundamental mode is $4.1 \mathrm{~Hz}$, and the band-pass filter width is determined from 0 to $10 \mathrm{~Hz}$ using the successive approximation approach. An $\mathrm{RD}$ function with a trigger value of $6.5 \times 10^{-4} \mathrm{~m} / \mathrm{s}^{2}$ and a time segment length of 10 seconds was extracted from the filtered acceleration data as shown in Figure 8(c), and the Curve Fitting Technique was applied to fit the first ten cycles as shown in Figure 8(d). 
The estimated amplitude-dependent natural frequencies and damping ratios are shown in Figure 9(c).

3.3. Ambient Vibration Test Results. Amplitude-dependent fundamental natural frequencies and damping ratios were estimated from ambient vibration test data using the proposed procedure for the test cases. The response acceleration data at the top/center of the roof was adopted for analysis. The mean values, standard deviations, and variable coefficients of the fundamental natural frequencies and damping ratios are presented in Table 3 with corresponding peak acceleration values. As shown, the addition of cladding components to the steel frame results in higher natural frequencies than that of the bare steel frame. With those cladding components, the fundamental natural frequencies of the test cases ranged between $3.59 \mathrm{~Hz}$ and $4.65 \mathrm{~Hz}$, while the natural frequency of the bare steel frame was only $3.40 \mathrm{~Hz}$; that is, the natural frequencies increased by about $5 \%$ to $40 \%$. The increase in natural frequencies indicates that the cladding components had a significant effect in stiffening the structure and increased in the stiffness relative to the mass of the steel frame, and they also greatly increased the damping ratios. The damping ratios of the bare steel frame were only $0.1 \%$. However, with the inclusion of cladding components, they ranged between $0.9 \%$ and $2.0 \%$; that is, they were 8 to 18 times larger than that of the bare frame. The contribution of cladding components to structural damping was remarkable.

Figure 9 illustrates the estimated dynamic parameters with respect to the magnitudes of acceleration response. In the ambient vibration tests, the magnitudes of acceleration response were very small. Thus, the amplitude dependency of the dynamic parameters was examined in a low- and narrowamplitude range, which mainly varied between 0 and $0.5 \times$ $10^{-2} \mathrm{~m} / \mathrm{s}^{2}$. The fundamental natural frequencies are generally observed to be constant in all test cases, and damping ratios show a slight scatter. Especially in Case 5, a decrease of damping ratio with respect to acceleration amplitude can be noticed. Generally, constant natural frequencies and slight amplitude dependency of damping ratios can be observed from ambient vibration tests for low excitation amplitude.

\section{Processing of Free Vibration Test Data and Results}

4.1. Description of Data Processing Procedure. Free vibration tests were conducted following the ambient vibration test for each case and three times at the fundamental resonance frequency of each case to obtain more data and reduce errors.

In order to estimate amplitude-dependent dynamic characteristics, free vibration test data was processed in the following steps. The response acceleration data was passed through a band-pass filter and the contribution of the target mode was isolated at first. Then, the filtered free vibration signal was decomposed into a set of subsignals, and each subsignal was defined as the oscillation cycle between two successive positive peaks. Afterwards, natural frequencies and damping ratios could be evaluated from subsignals by using Curve Fitting Technique, and corresponding amplitude could be defined as the starting positive peak of each subsignal, so that amplitude-dependent dynamic characteristics could be estimated from the free vibration test data.

Figure 10 illustrates the application of the processing procedure suggested above to one set of free vibration test data of Case 3. The time history of response acceleration data measured at the center of top roof is shown in Figure 10(a), and corresponding Fourier spectrum is shown in Figure 10(b). The filtered free vibration signal is shown in Figure 10 (c) and is decomposed into a series of subsignals. A Curve Fitting Technique is applied to fit the first subsignal as shown in Figure 10(d). The estimated amplitude-dependent natural frequencies and damping ratios can be checked in Figures 11(c) and 12(c), respectively.

4.2. Free Vibration Test Results. Amplitude-dependent fundamental natural frequencies and damping ratios estimated from free vibration test data are presented in this section, and Table 4 summarizes the estimated fundamental natural frequencies and damping ratios of test cases with corresponding peak acceleration values. It can be appreciated that, with the inclusion of the cladding components, the fundamental frequencies of the steel frame were higher than that calculated from the bare frame, indicating that cladding components provide an apparent increase in stiffness, which far outweighs the increase in mass. Meanwhile, the results estimated from the free vibration test data demonstrate that cladding components make a big contribution to structural damping. The estimated fundamental damping ratio of the bare frame only varies from $0.1 \%$ to $0.5 \%$, but a significant increase in damping ratios is observed with the addition of cladding components. The upper bound values of damping ratios in other test cases were found to be 4 to 8 times larger than that of the bare frame. The addition of cladding components to the steel frame increased the dissipation of energy in the structure, thus increasing the structural damping.

Figures 11 and 12 illustrate the amplitude dependency of fundamental natural frequencies and damping ratios estimated from free vibration test data, respectively. In the free vibration tests, the magnitudes of acceleration response are much wider than those in the ambient vibration tests. Thus, significant amplitude dependency of dynamic characteristics can be observed in the figures. As shown in Figure 11, the fundamental natural frequencies generally decrease with amplitude, so that the natural frequencies in the highamplitude range are appropriately $0.2 \sim 0.5 \mathrm{~Hz}$ lower than the initial values for most cases. However, it should be noted that there is almost no amplitude dependency of natural frequencies for the bare steel frame in Figure 11(a). A similar phenomenon has also been observed for damping ratios in Figure 12. Damping ratios are observed to generally increase with amplitude in the low-amplitude range and then decrease with increasing amplitude for most cases. However, the estimated damping ratios of the bare steel frame hardly change with amplitude in Figure 12(a). Considering that the amplitude dependency of dynamic characteristics appears in test cases with inclusion of cladding components, it is clear that the addition of cladding components to the steel frame is the cause of the amplitude dependency 


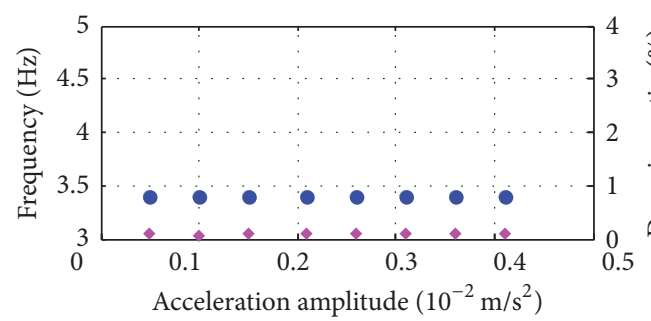

Frequency

- Damping

(a) Case 1

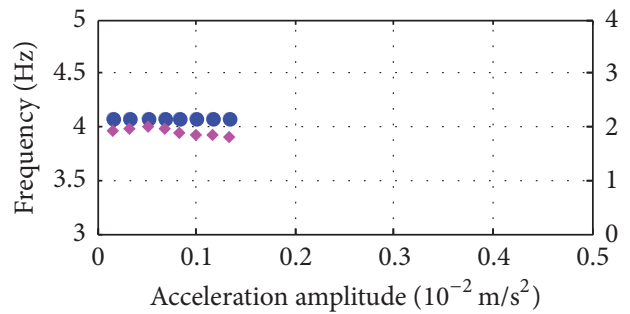

- Frequency

- Damping

(c) Case 3

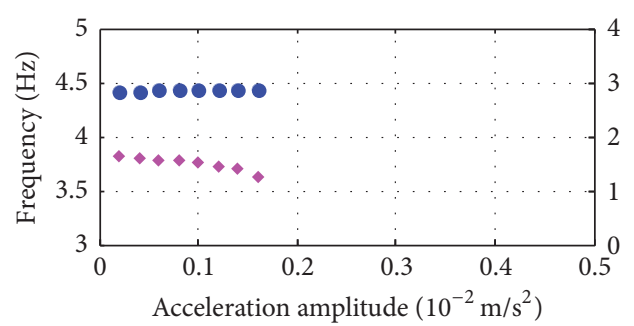

- Frequency

- Damping

(e) Case 5

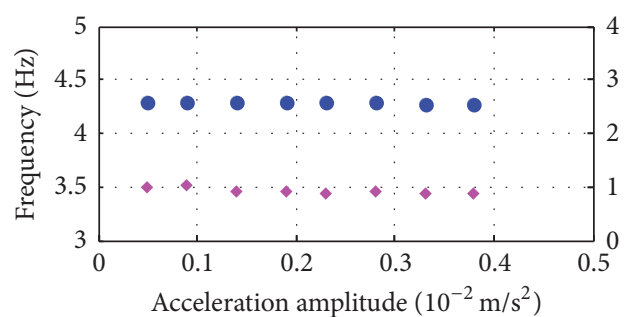

- Frequency

- Damping

(g) Case 7

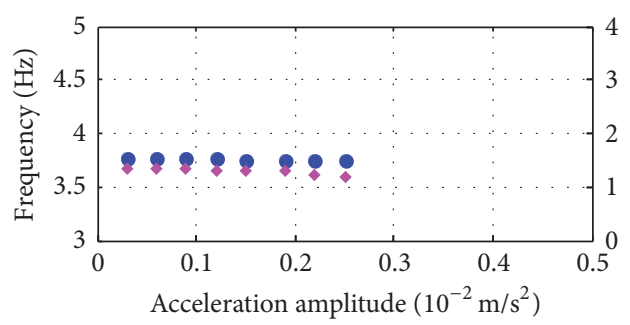

- Frequency

- Damping

(i) Case 9

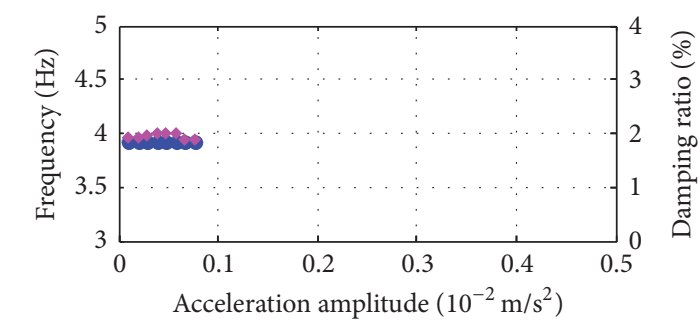

- Frequency

- Damping

(b) Case 2

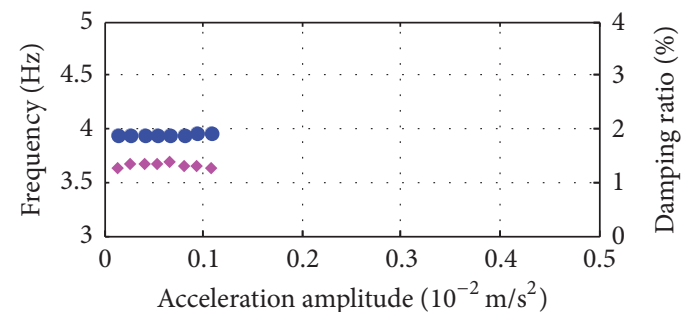

- Frequency

- Damping

(d) Case 4

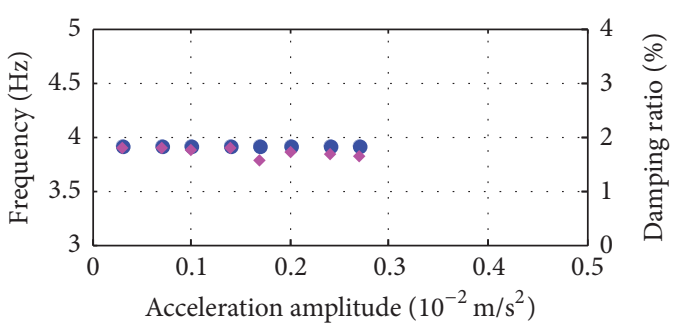

- Frequency

- Damping

(f) Case 6

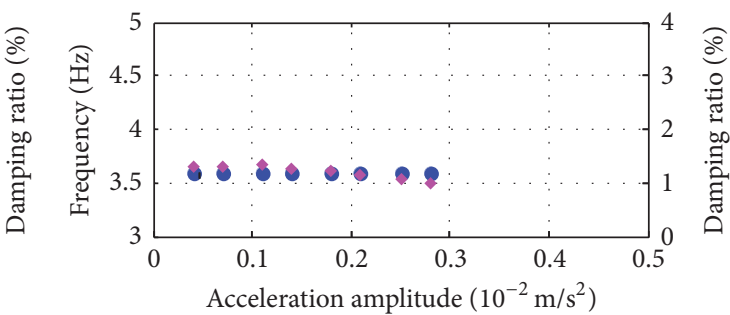

- Frequency

- Damping

(h) Case 8

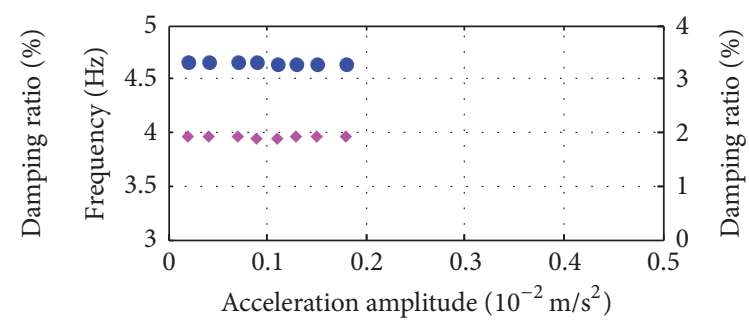

- Frequency

- Damping

(j) Case 10

Figure 9: Amplitude-dependent dynamic characteristics estimated from ambient vibration tests. 
TABLE 3: Natural frequencies and damping ratios estimated from ambient vibration tests.

\begin{tabular}{lcccccc}
\hline Case & $\begin{array}{c}\text { Peak acc. } \\
\left(\times 10^{-2} \mathrm{~m} / \mathrm{s}^{2}\right)\end{array}$ & $f(\mathrm{~Hz})$ & $\begin{array}{c}\text { Frequency } \\
\sigma_{f}(\mathrm{~Hz})\end{array}$ & COV $(\%)$ & $\zeta(\%)$ & \multicolumn{2}{c}{ Damping ratio } \\
$\sigma_{\zeta}(\%)$
\end{tabular}

Note: $f$ denotes mean value of natural frequency; $\zeta$ denotes mean value of damping ratio; $\sigma$ denotes standard deviation; and COV denotes coefficient of variation $=$ standard deviation $/$ mean.

TABLE 4: Natural frequencies and damping ratios estimated from free vibration tests.

\begin{tabular}{lccccc}
\hline Case & $\begin{array}{c}\text { Peak acc. } \\
\left(\times 10^{-2} \mathrm{~m} / \mathrm{s}^{2}\right)\end{array}$ & \multicolumn{3}{c}{ Frequency } & \multicolumn{2}{c}{$\begin{array}{c}\text { Damping ratio } \\
\zeta(\%)\end{array}$} \\
\hline 1 & 96.2 & $f(\mathrm{~Hz})$ & $\sigma_{f}(\mathrm{~Hz})$ COV $(\%)$ & $0.1 \sim 0.5$ \\
2 & 36.1 & 3.41 & 0.007 & 0.21 & $1.5 \sim 3.2$ \\
3 & 32.5 & 3.63 & 0.132 & 3.64 & $1.3 \sim 3.1$ \\
4 & 33.5 & 3.77 & 0.128 & 3.40 & $0.8 \sim 3.4$ \\
5 & 32.1 & 3.81 & 0.146 & 3.83 & $0.8 \sim 3.0$ \\
6 & 44.9 & 4.16 & 0.118 & 2.84 & $0.7 \sim 2.8$ \\
7 & 39.8 & 3.70 & 0.106 & 2.86 & $0.5 \sim 2.7$ \\
8 & 94.0 & 3.95 & 0.100 & 2.53 & $0.5 \sim 2.0$ \\
9 & 94.3 & 3.44 & 0.042 & 1.22 & $0.5 \sim 2.2$ \\
\hline
\end{tabular}

Note: $f$ denotes mean value of natural frequency; $\sigma$ denotes standard deviation; and COV denotes coefficient of variation.

for dynamic characteristics, while dynamic parameters are almost independent of response amplitude for the bare steel frame.

\section{Discussion}

5.1. Effect of Precast Cladding Systems on Evaluation of Dynamic Parameters. The main objective of the work presented in this paper was to evaluate the effect of precast cladding systems on the dynamic characteristics of steel frame buildings. To improve understanding of the effect of cladding components, this section starts by comparing the natural frequencies and damping ratios provided by ambient and free vibration tests. The mean values of the results estimated from ambient vibration tests are adopted, and scopes of the results estimated from free vibration tests are given for comparison. In addition, the estimated results corresponding to the response amplitudes of $5 \times 10^{-2} \mathrm{~m} / \mathrm{s}^{2}$ and $20 \times 10^{-2} \mathrm{~m} / \mathrm{s}^{2}$ in free vibration tests are presented, which represent the dynamic properties in the low- and highamplitude range, respectively.
Figure 13 illustrates the effect of ALC external wall cladding panels on the dynamic characteristics of the steel frame. Different numbers of ALC external wall cladding layers were considered in constructing Case 2 and Case 10, and this allowed investigation of the effect of ALC external wall claddings. From Figure 13(a) it is found that the natural frequency generally increases with the addition of ALC external wall cladding layers. The maximum fundamental natural frequency estimated from free vibration test data increases by approximately $20 \%$ and $40 \%$, respectively, with the addition of single layer ALC claddings and double layers. From Figure 13(b) it is found that damping ratio also generally increases with the addition of ALC cladding layers. A dramatic increase in damping ratio appears as single layer ALC claddings are attached to the bare frame in Case 2, and free vibration maximum fundamental damping ratios of Case 2 and Case 10 are almost 7 and 8 times larger than that of the bare frame, respectively. Although the damping ratio corresponding to the amplitude of $5 \times 10^{-2} \mathrm{~m} / \mathrm{s}^{2}$ decreases from Case 2 to Case 10, the reason for this decrease is the difference between the amplitude dependencies of Case 2 


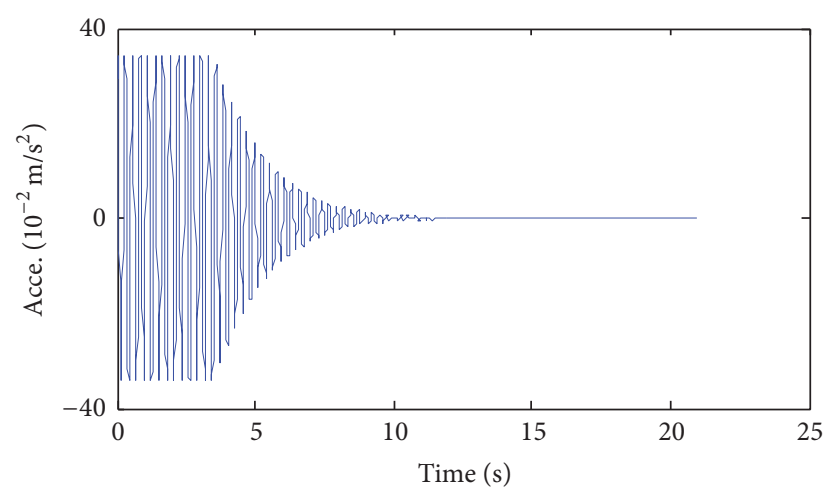

(a) Time history of response acceleration data on top floor

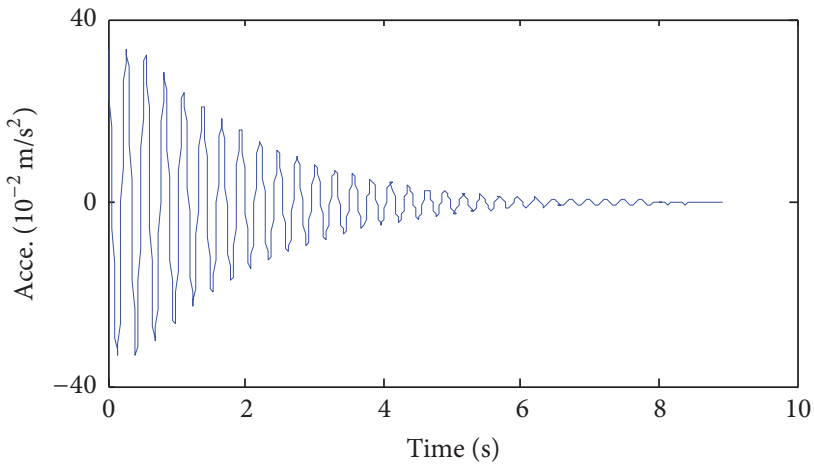

(c) Filtered free vibration data

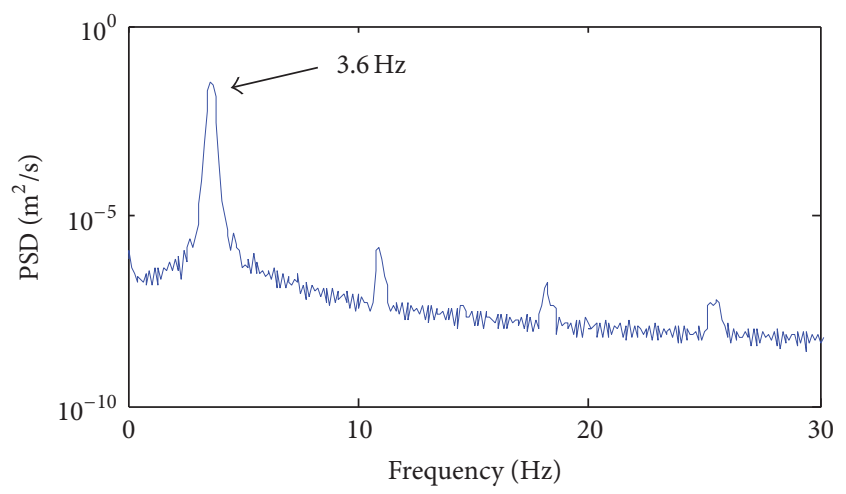

(b) Fourier spectrum of response acceleration data

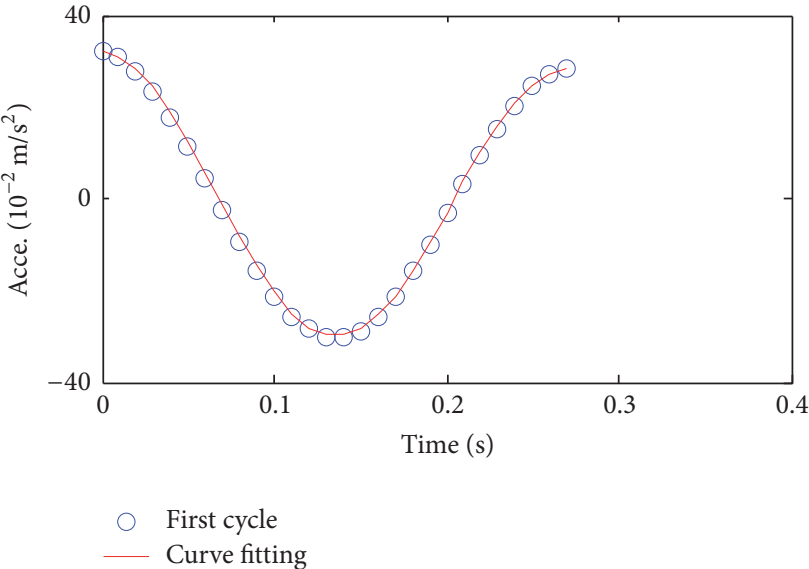

(d) Curving fitting result

FIGURE 10: Data processing procedure of free vibration test data of Case 3.

and Case 10, which can be checked in Figure 12. Therefore, the addition of ALC claddings to the steel frame provided a large increase in stiffness, which is because the ALC external claddings became active in resisting lateral loads. Meanwhile, the addition of ALC claddings increases the number of friction surfaces, so that structural damping is enhanced.

Figure 14 illustrates the effect of gypsum plasterboard on the dynamic characteristics of the steel frame. In order to explain these effects, Case 2 to Case 9 are classified into four groups, and corresponding results are compared in pairs. Each group includes two test cases: one with the addition of plasterboard and the other without. The comparisons presented in Figure 14(a) show that all the fundamental natural frequencies of test cases with plasterboard are higher than the corresponding estimates of cases without plasterboard. The increase in free vibration maximum natural frequencies provided by the plasterboard is approximately in the range from $3 \%$ to $9 \%$. The effect of plasterboard on damping ratio is compared in Figure 14(b), and the damping ratio is generally found to decrease with the addition of plasterboard. The reason for this decrease is that the rotational displacement of ALC external claddings was restricted by the addition of plasterboard. As mentioned in the Introduction and observed in this study, damping ratio develops with response amplitude. At the design stage, each ALC panel is allowed to rotate freely with the story drift of the structural frame. However, when plasterboard is attached to ALC claddings through wood stud framings, those wood stud framings provide a combination of ALC panels. Thus, the rotational capacity of ALC panels is limited, and damping ratio declines with the addition of plasterboard. From the above comparisons, it can be concluded that inclusion of plasterboard in the steel frame results in an increase in stiffness relative to mass, but interactions between plasterboard and ALC claddings have a negative effect on damping ratios.

Figure 15 illustrates the effect of window glazing systems on the dynamic characteristics of the steel frame. Window glazing systems in precast cladding systems are inevitable due to functional and ventilation requirements, and introducing window openings in precast cladding systems adds complexity in structural behavior. In order to examine the effect of window glazing systems, Case 2 to Case 9 are classified into two groups, and a similar tendency of frequency and damping ratio can be observed in these two groups, respectively. As observed in Figure 15(a), an increase in natural frequency is obtained with the addition of small window openings. These increases are about $5 \%$ and $10 \%$, respectively, in the two groups. Frequency decreases as window size increases. The effect of a window glazing system on damping ratio is illustrated in Figure 15(b). As shown, damping ratio generally 


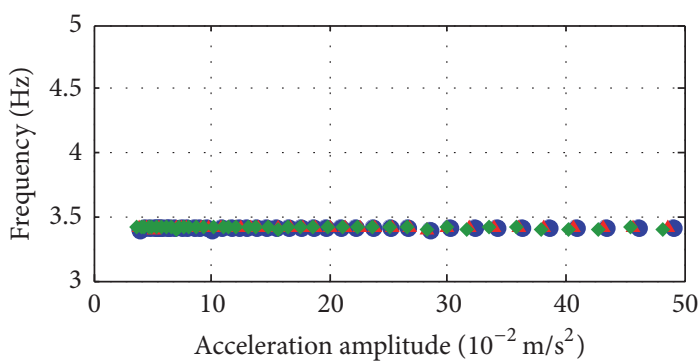

- Set 1

- Set 2

- Set 3

(a) Case 1

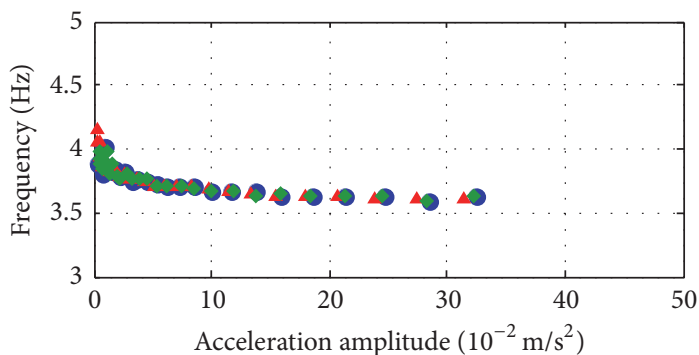

- Set 1

- Set 2

- Set 3

(c) Case 3

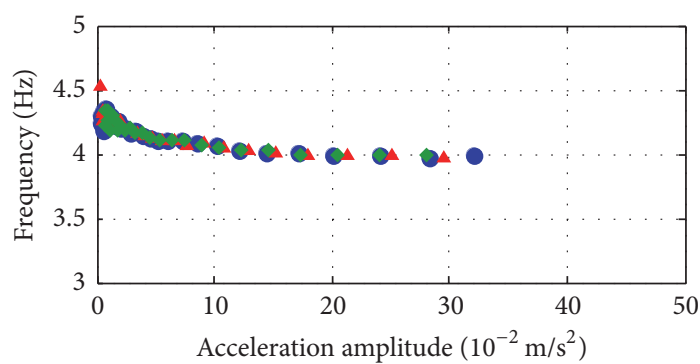

- Set 1

- Set 2

- Set 3

(e) Case 5

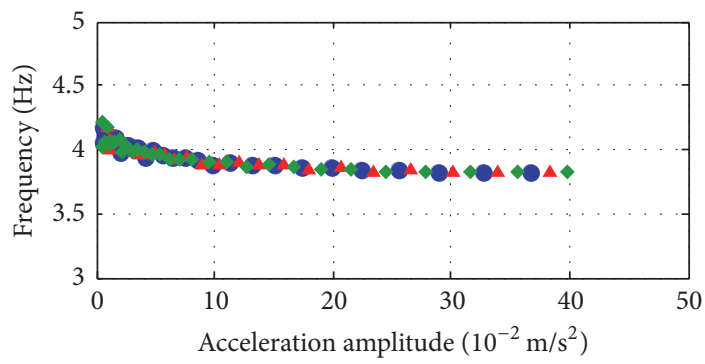

- Set 1

- Set 2

- Set 3

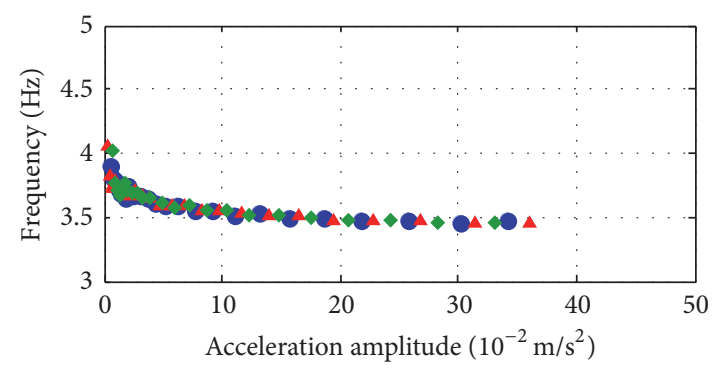

- Set 1

- Set 2

- Set 3

(b) Case 2

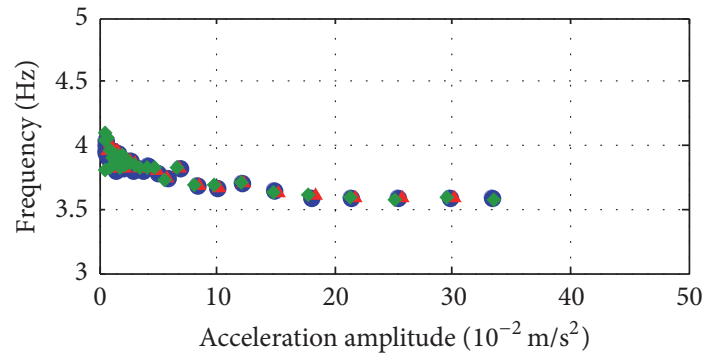

- Set 1

- Set 2

- Set 3

(d) Case 4

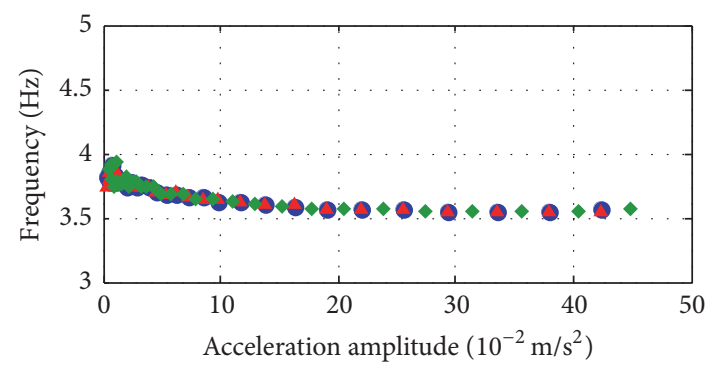

- Set 1

- Set 2

- Set 3

(f) Case 6

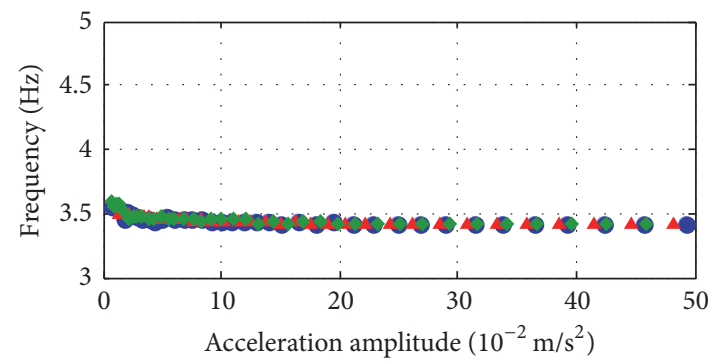

- Set 1

- Set 2

- Set 3

(g) Case 7

(h) Case 8

FIgURE 11: Continued. 


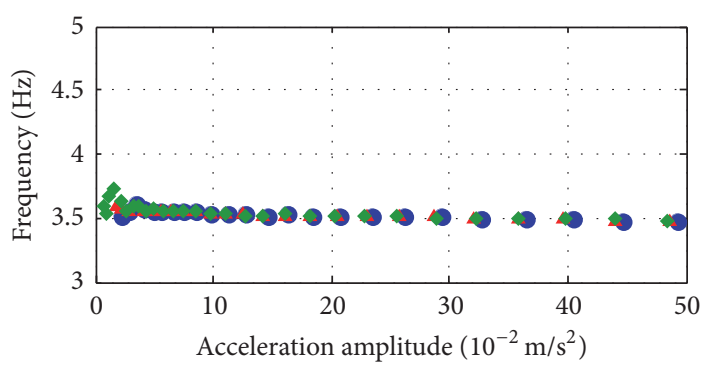

- Set 1

- Set 2

- Set 3

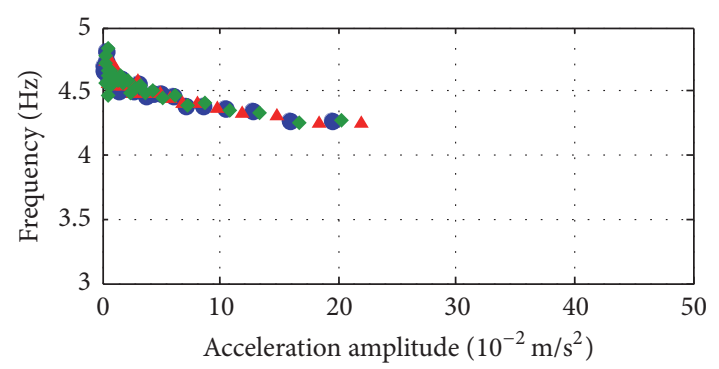

- Set 1

- Set 2

- Set 3

(i) Case 9

(j) Case 10

FIGURE 11: Amplitude-dependent natural frequencies estimated from free vibration tests.

decreases as window size increases. From the comparisons shown in Figure 15, it is realized that window glazing systems integrated into precast cladding systems help to stiffen the steel frame, because the window frames used to hold windows in place are fixed to steel beams and hence provide lateral stiffness to the steel frame. Meanwhile, window openings reduce the effective area of ALC claddings and plasterboard. Thus, the stiffness contribution of precast cladding systems decreases when window openings become larger. Furthermore, window openings reduce the number of friction surfaces between primary structural members and the precast cladding systems, so structural damping decreases when window size increases.

The comparisons above demonstrate that the effects of precast cladding systems on dynamic characteristics of steel frames far exceed those that had been anticipated previously. As current design is based on the assumption that the steel frame carries the lateral loads and precast cladding systems are considered as nonstructural components, it can be appreciated that there is a huge discrepancy between design and actual performance of steel frame buildings. For accurate design of steel frame structures, it is essential to take into account the effect of precast cladding systems on dynamic characteristics in current design practice.

\subsection{Effect of Precast Cladding Systems on Evaluation of Lateral} Stiffness. The test steel frame with precast cladding systems can be simplified analytically as a single degree of freedom system. Hence, the effective lateral stiffness of the bare steel frame and the steel frame with addition of different parts of precast cladding systems can be determined in accordance with the effective mass and the fundamental natural frequency, based on the idealization of a lightly damped single degree of freedom system using

$$
K=M_{e}(2 \pi f)^{2},
$$

where $K$ is the stiffness, $M_{e}$ is the calculated effective mass, and $f$ is the fundamental natural frequency.

Given the effective masses and the fundamental natural frequencies measured in free vibration tests, values of lateral stiffness of the bare steel frame and the steel frame with precast cladding systems are evaluated, and the effects of ALC claddings, plasterboard, and window glazing systems on lateral stiffness are illustrated in Figures 16, 17, and 18, respectively. Figure 16 illustrates the effect of ALC external wall cladding panels on lateral stiffness of the steel frame. It can be observed that ALC cladding panels provide a big increase in lateral stiffness, which far outweighs the increase in mass. The lateral stiffness of the bare frame is calculated to be $4.03 \times 10^{6} \mathrm{~N} / \mathrm{m}$, while the lateral stiffness of the steel frame with ALC claddings in Case 2 and Case 10 is $4.88 \times$ $10^{6} \mathrm{~N} / \mathrm{m}$ and $7.86 \times 10^{6} \mathrm{~N} / \mathrm{m}$, respectively. The lateral stiffness increases by approximately $21 \%$ and $95 \%$, respectively, with the addition of single layer ALC claddings and double layers. Figure 17 illustrates the effect of gypsum plasterboard on lateral stiffness of the steel frame. The contribution of plasterboard on lateral stiffness is compared in four groups, and the comparisons show that addition of plasterboard in the steel frame results in a greater lateral stiffness. The increases in lateral stiffness provided by plasterboard are $11 \%, 23 \%, 15 \%$, and $6 \%$ in the four groups, respectively. Figure 18 illustrates the effect of window glazing systems on lateral stiffness of the steel frame. The effect of window glazing systems on lateral stiffness is compared in two groups, and a similar tendency can be observed. An increase in lateral stiffness is observed when small window openings are added to the steel frame. The increases are $10 \%$ and $22 \%$ in the two groups, respectively. Afterwards, the stiffness contribution of window glazing systems decreases when middle and large window openings are added to the steel frame.

The evaluation of lateral stiffness demonstrates that precast cladding systems including ALC external wall cladding panels, gypsum plasterboard interior linings, and window glazing systems contribute significantly to structural stiffness. The significant stiffness contribution indicates that seismic loads may be underestimated while response displacement may be overestimated on condition that the effects of precast cladding systems are ignored in the design of steel frame structures. 


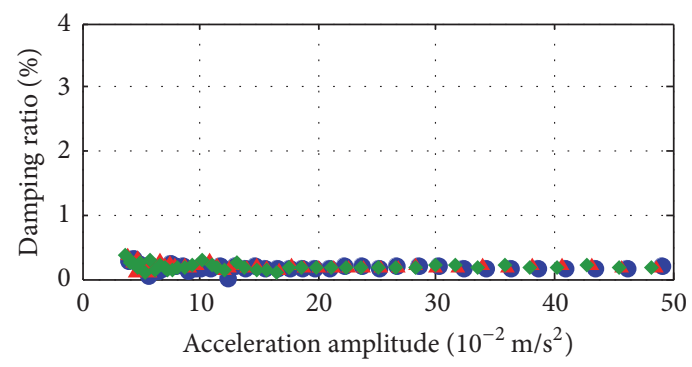

- Set 1

- Set 2

- Set 3

(a) Case 1

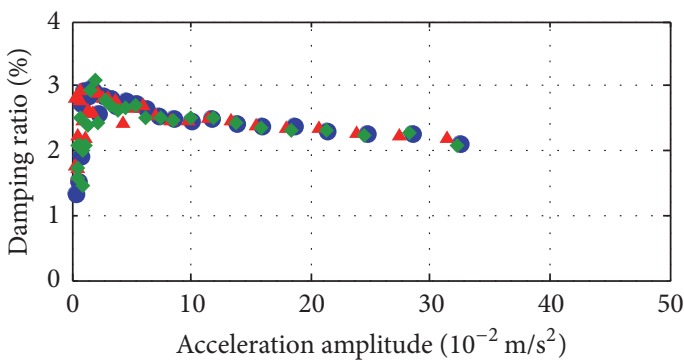

- Set 1

- Set 2

- Set 3

(c) Case 3

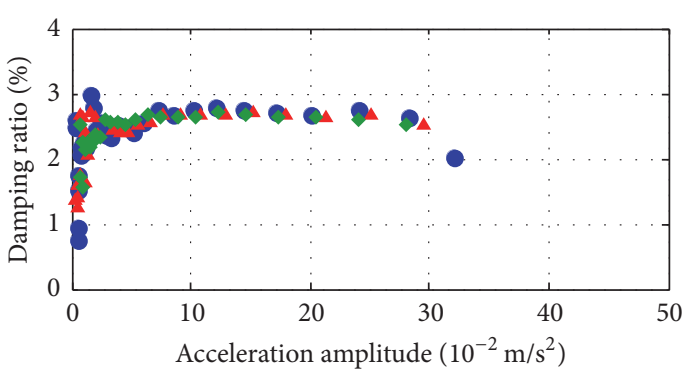

- Set 1

- Set 2

- Set 3

(e) Case 5

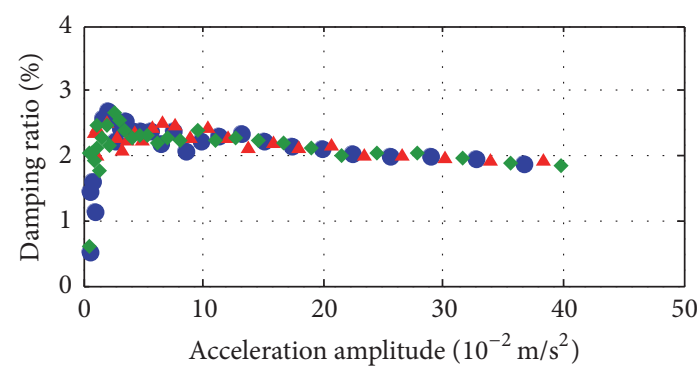

- Set 1

- Set 2

- Set 3

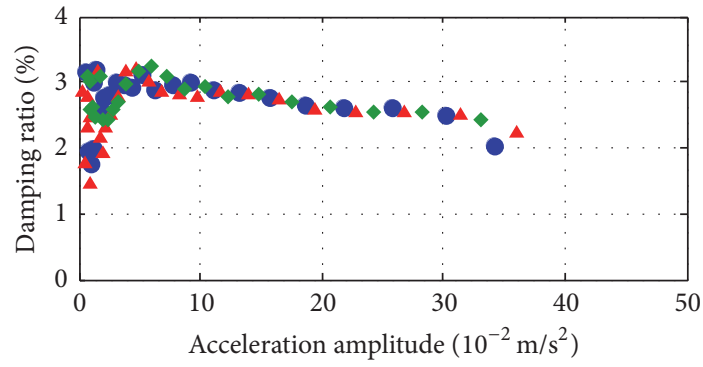

- Set 1

- Set 2

- Set 3

(b) Case 2

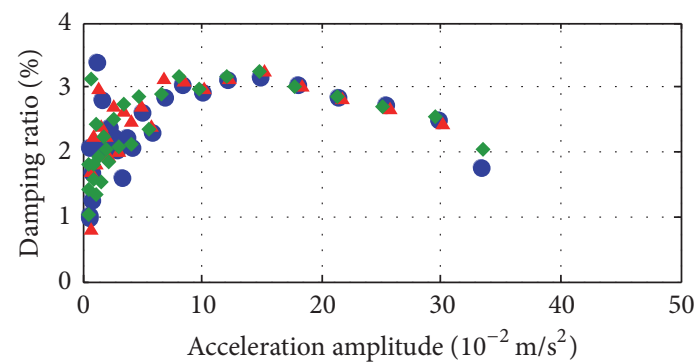

- Set 1

- Set 2

- Set 3

(d) Case 4

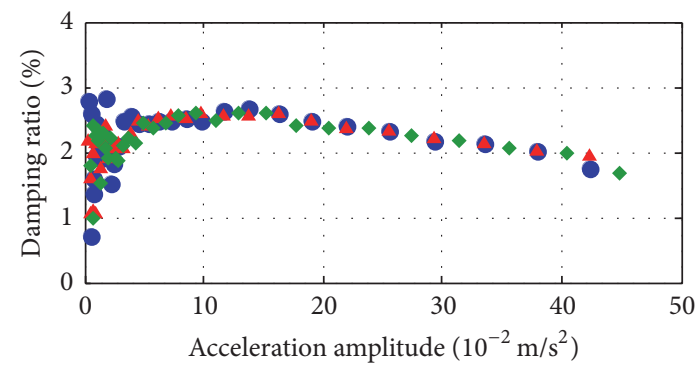

- Set 1

- Set 2

- Set 3

(f) Case 6

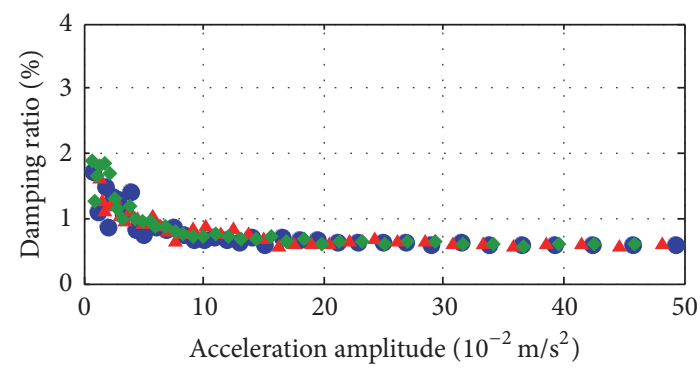

- Set 1

- Set 2

- Set 3

(h) Case 8

(g) Case 7

FIGURE 12: Continued. 


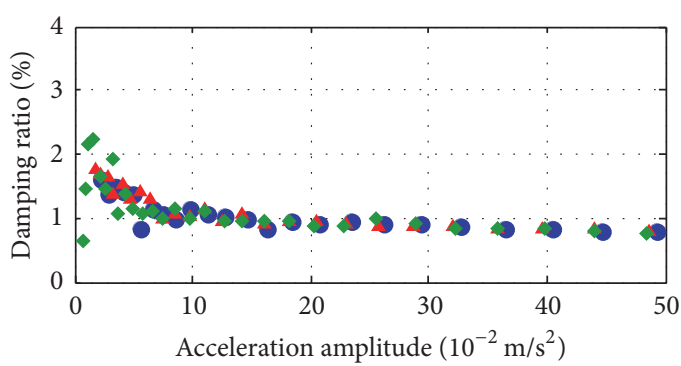

- Set 1

- Set 2

- Set 3

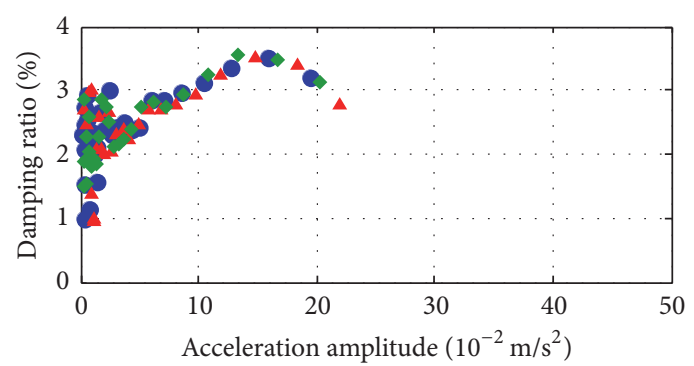

- Set 1

- Set 2

- Set 3

(i) Case 9

(j) Case 10

FIGURE 12: Amplitude-dependent damping ratios estimated from free vibration tests.

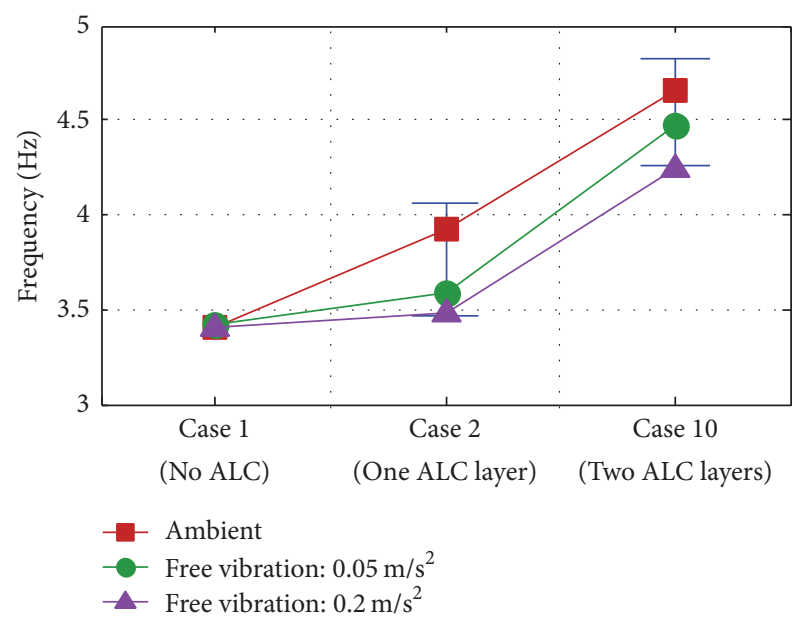

(a) Fundamental natural frequency

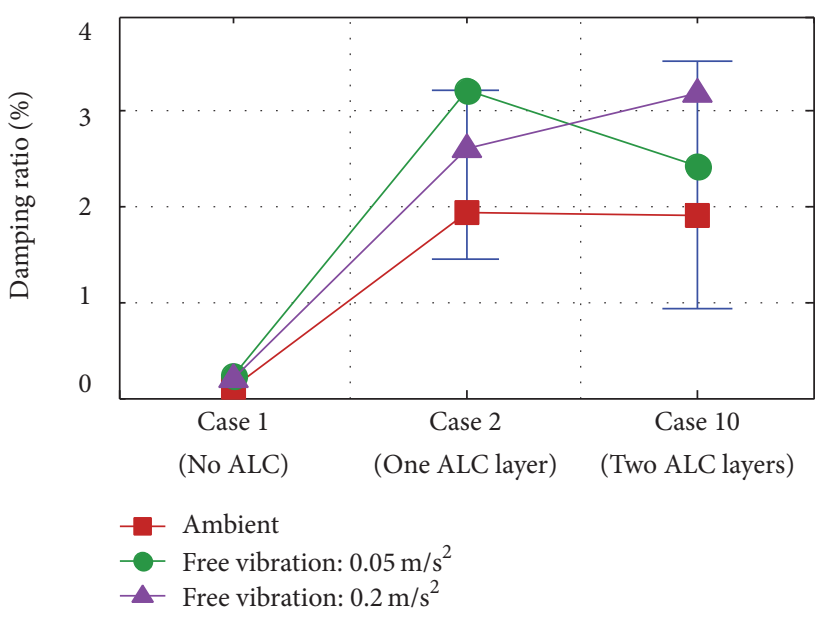

(b) Fundamental damping ratio

FIGURE 13: Effect of ALC external claddings on dynamic characteristics of steel frame.

5.3. Effect of Precast Cladding Systems on Amplitude Dependency of Dynamic Characteristics. Another important objective of this study was to examine the amplitude dependency of dynamic characteristics. The results of free vibration tests illustrated in Figures 11 and 12 show significant amplitude dependency of natural frequency and damping ratio and hence provide a basis for a better understanding of the amplitude dependency of dynamic characteristics. By comparing the amplitude-dependent natural frequency and damping ratio of the bare steel frame with those of other test cases, it is observed that amplitude dependency of dynamic characteristics takes place with the existence of precast cladding systems. As observed in Figures 11(a) and 12(a), both natural frequency and damping ratio of the bare steel frame remain almost the same with gradually changing amplitude. However, when precast cladding systems are attached to the steel frame in other test cases, those estimated results show nonlinear characteristics with respect to the response magnitudes. The effect of precast cladding systems on amplitude dependency of dynamic characteristics can be explained by the stickslip mechanism that happens at the interfaces between primary structural members and secondary components. This mechanism assumes that the contact surfaces between primary structural members and secondary components are in stuck or slip condition. As vibration amplitude increases, the contact surfaces gradually change from stuck condition to slip condition, which leads to an increase in friction but loss of stiffness contribution from secondary members. Thus, dynamic parameters develop with gradually changing amplitude.

Another important observation is the tendency of dynamic characteristics with increase in response amplitude. In order to explain this tendency, Figure 19 gives a typical amplitude dependency of natural frequency and damping ratio estimated from the free vibration test data of Case 3 . It can be appreciated that natural frequency tends to decrease with increasing amplitude, while damping ratio first increases and then decreases with increasing response amplitude. The decrease of natural frequency can be expressed by the stickslip mechanism. The stick-slip mechanism assumes that the stick-slip contact surfaces between primary structural members and secondary components are in stuck or slip 


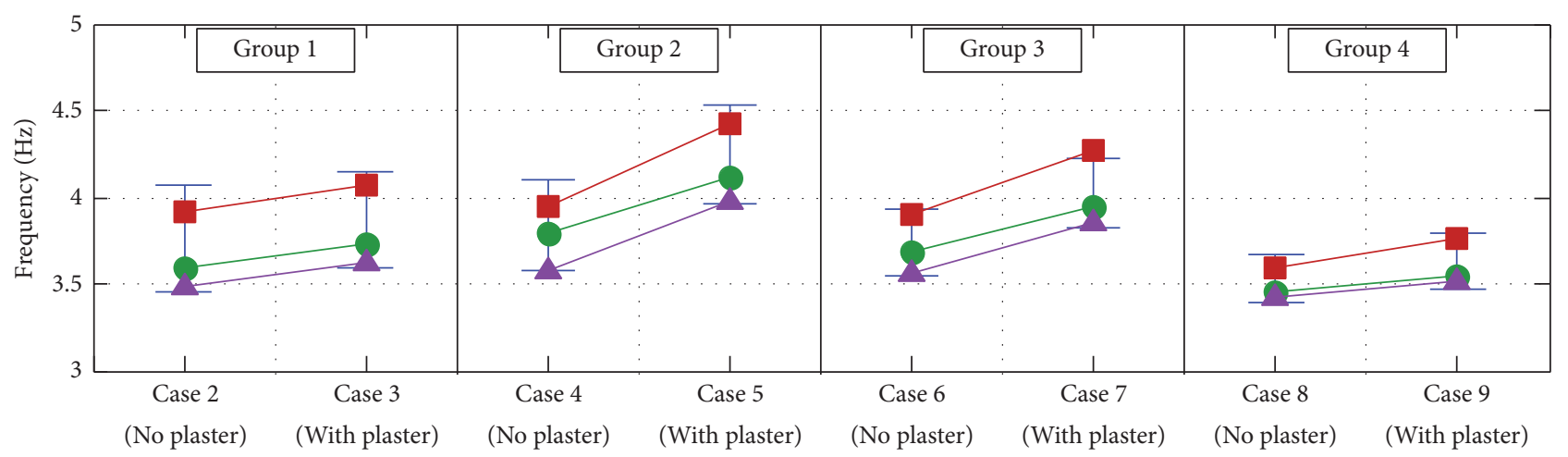

(a) Fundamental natural frequency

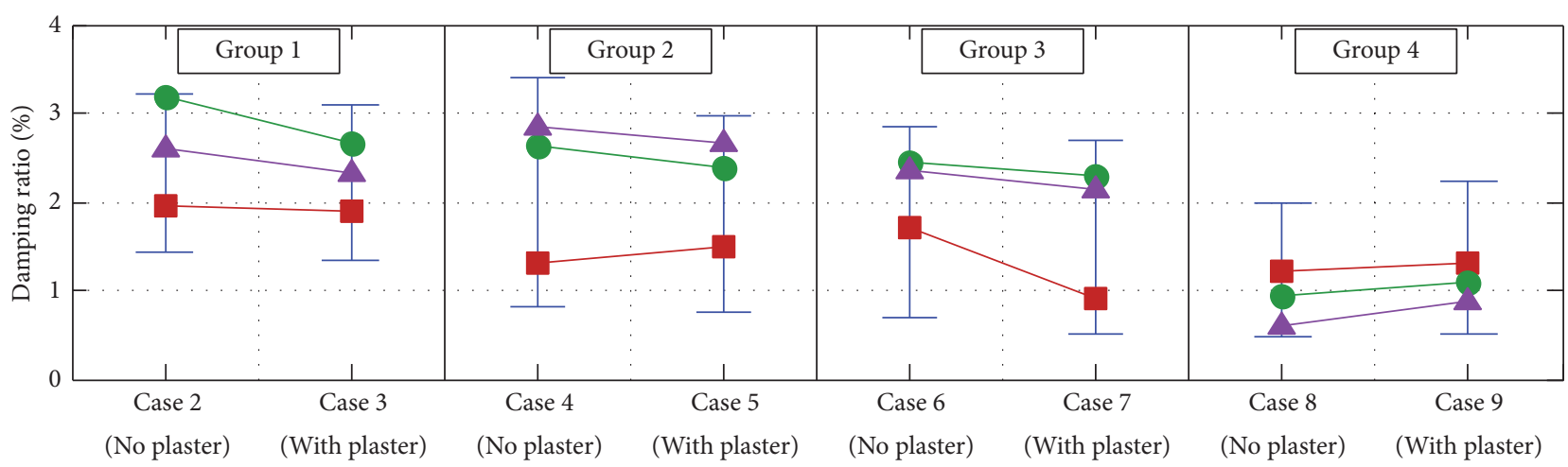

(b) Fundamental damping ratio

FIGURE 14: Effect of plasterboard on dynamic characteristics of steel frame.

condition. In low-amplitude range, almost all contact surfaces are stuck and do not move, and the secondary members contribute to structural stiffness. As vibration amplitude increases, stick-slip contact surfaces begin to slip at their particular amplitudes; thus the effective contribution of secondary components to the total system stiffness starts to decrease. As the number of slipping contact surfaces increases with amplitude, natural frequency decreases with amplitude. Furthermore, it is noteworthy that an obvious decreasing trend of damping ratio is observed, which is quite different from early assumptions. The fundamental damping ratio reaches its maximum at around the response acceleration $a_{H} \approx 0.02 \mathrm{~m} / \mathrm{s}^{2}$. Thus, the tip response displacement $x_{H} \approx$ $a_{H} /\left(2 \pi f_{1}\right)^{2}$ is roughly estimated at $3.9 \times 10^{-5} \mathrm{~m}$ when natural frequency $f_{1}$ is considered as $3.6 \mathrm{~Hz}$, and the critical tip drift ratio is estimated at $x_{H} / H \approx 1.25 \times 10^{-5}$. Although earlier damping predictors usually assume that damping ratio increases in the low-amplitude range and remains at a constant maximum value up to the linear elastic limits of the primary structure $[13,14,23]$, it should be noted that most of those studies are based on measurements at relatively low amplitudes, and damping trends at higher amplitudes are assumed. So far, there is still insufficient damping ratio data at very high amplitudes, but the limited studies carried out in the relatively high-amplitude range have shown that damping ratio may decrease at higher amplitudes [11, 15, 24]. Tamura [25] clearly demonstrated that damping ratio first increases with amplitude but decreases after reaching the critical tip drift ratio, which is in accordance with the results in this study. It should be noted that damping ratio never keeps increasing with amplitude but may decrease after the response amplitude reaches the critical tip drift ratio.

5.4. Comparison of Results Provided by Ambient and Free Vibration Tests. The comparison of dynamic parameters provided by ambient vibration tests with those derived from free vibration tests is another issue that should be addressed. Table 5 compares the dynamic parameters of 10 test cases estimated from ambient vibration tests with corresponding results from free vibration tests. The estimated 


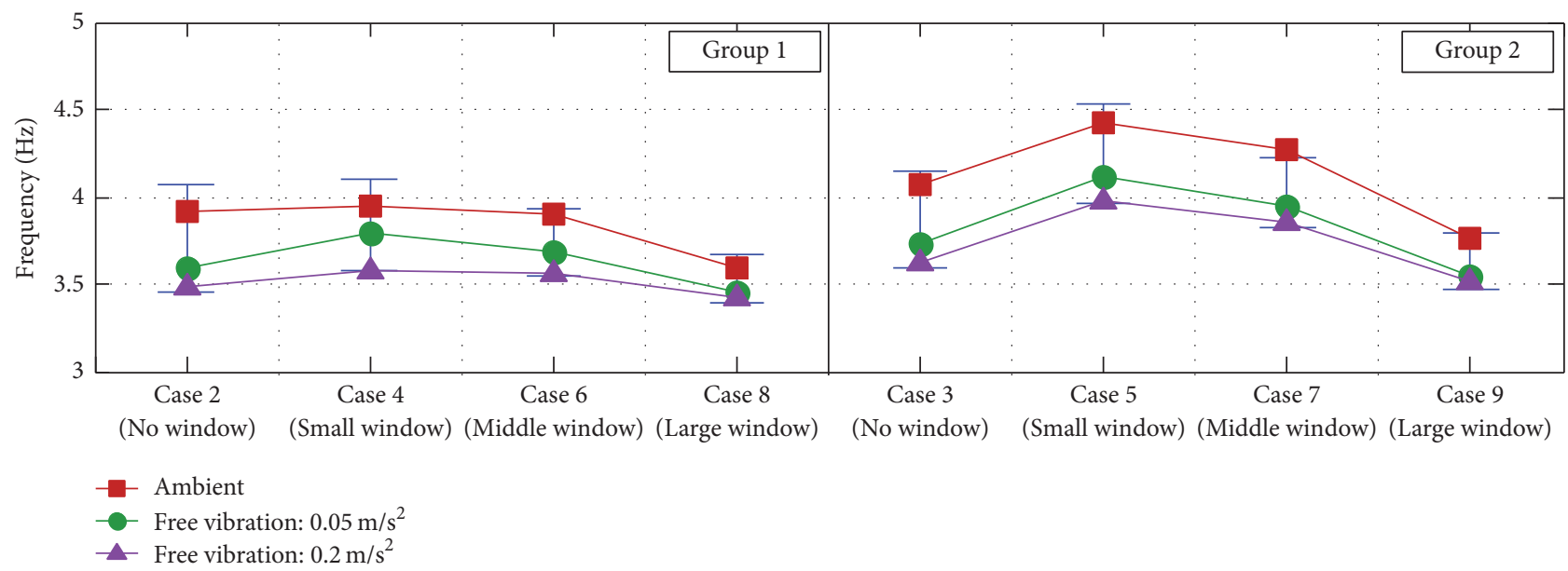

(a) Fundamental natural frequency

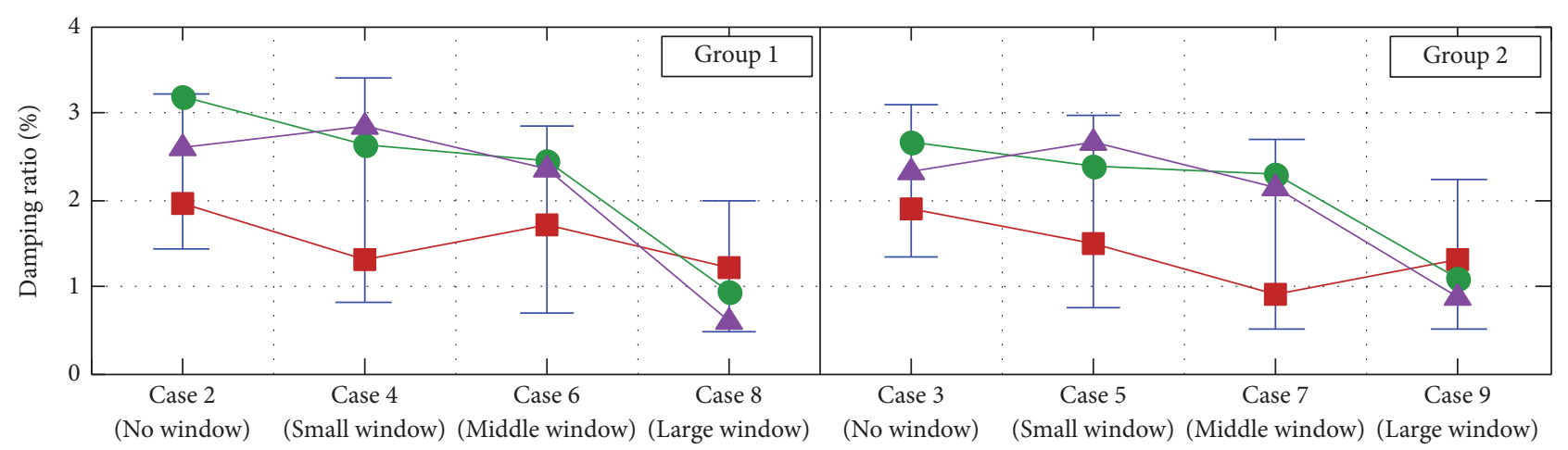

(b) Fundamental damping ratio

FIGURE 15: Effect of Window glazing systems on dynamic characteristics of steel frame.

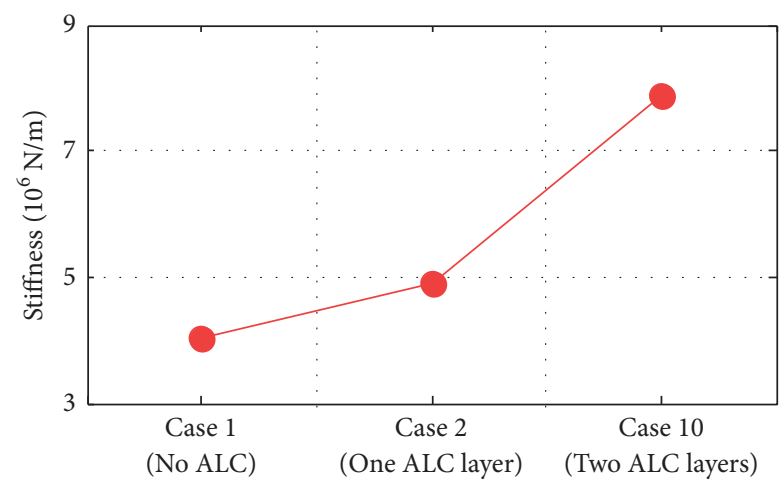

FIGURE 16: Effect of ALC external claddings on lateral stiffness.

natural frequencies and damping ratios are represented by the average values. The comparison between the results of AVT and FVT shows very little difference for the bare steel frame. But significant differences can be observed for other test cases with the addition of precast cladding systems. It is observed that natural frequencies estimated from ambient vibration tests are always $3 \%$ to $8 \%$ higher than those determined by free vibration tests, and the damping ratios estimated from ambient vibration tests are generally $21 \%$ to $57 \%$ lower than those determined by free vibration tests, except for Case 8 and Case 9.

The differences between the results estimated from ambient vibration test data and those determined by free vibration tests can be explained by the dependence of dynamic parameters with the vibration amplitude. As the response amplitudes involved in ambient vibration studies are significantly smaller than those for the free vibration tests, most contact surfaces between primary structural members and secondary components are still in the stuck condition. Thus, the frequencies determined by ambient vibration tests are higher than those determined by free vibration tests, while damping ratios determined by ambient vibration tests are lower than those determined by free vibration tests. The particular conditions observed for damping ratios of Case 8 and Case 9 in Table 5 


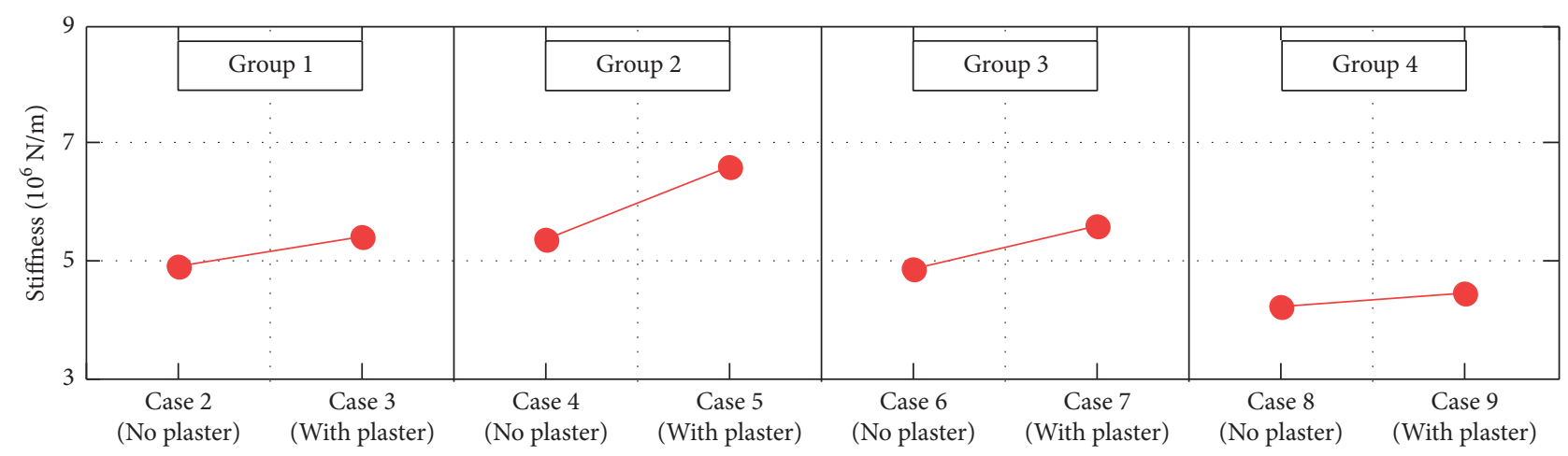

FIGURE 17: Effect of plasterboard on lateral stiffness.

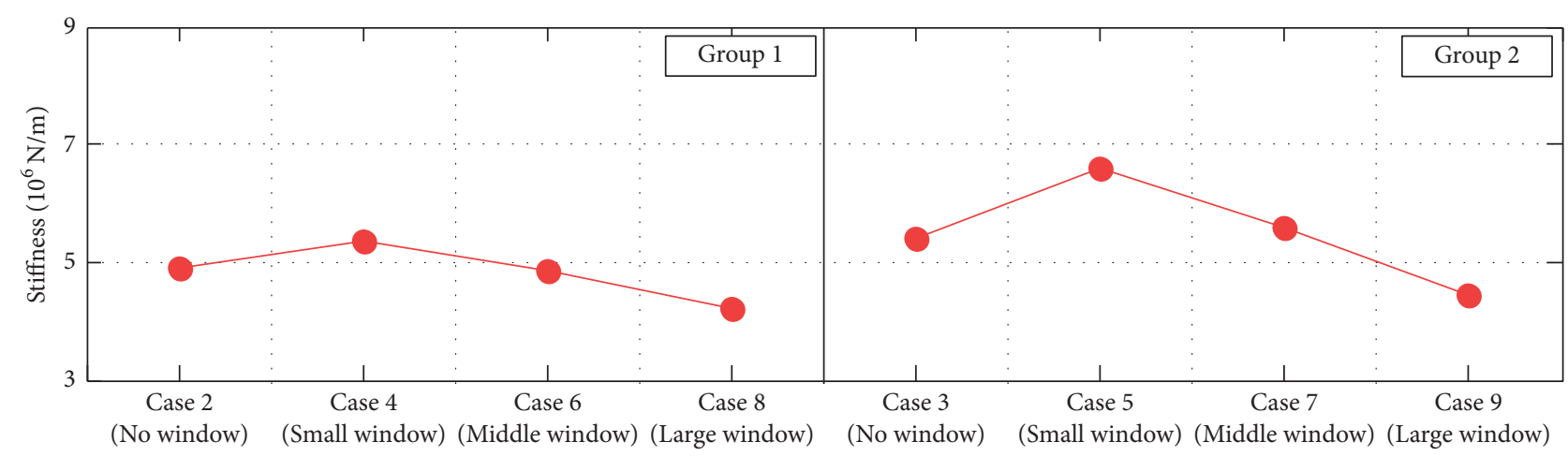

FIGURE 18: Effect of window glazing systems on lateral stiffness.

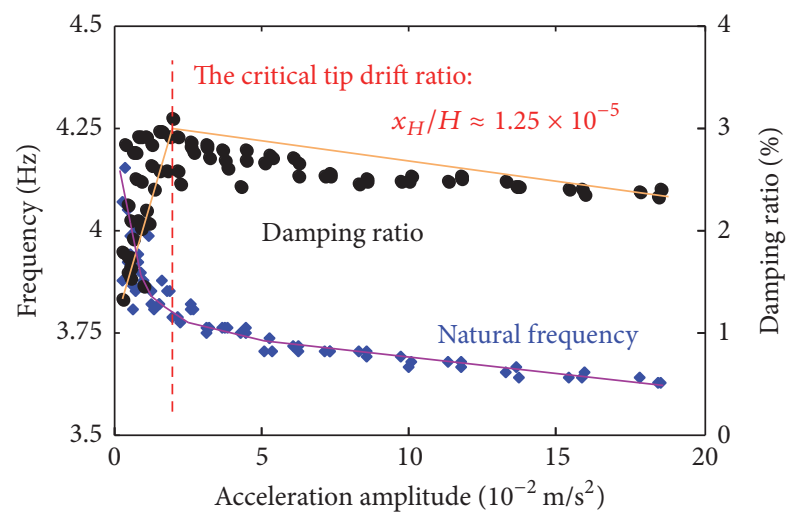

FIGURE 19: Amplitude dependency of natural frequency and damping ratio of Case 3.

are also attributed to the amplitude dependency of dynamic characteristics. The largest damping ratios estimated from free vibration test data are $2.0 \%$ and $2.2 \%$ for Case 8 and Case 9 , respectively, far exceeding those determined by ambient vibration tests. Structural identification through ambient vibrations has been successful in numerous cases, and the characteristics of the dynamic parameters determined by ambient vibration tests should be realized and considered in the following studies.

\section{Conclusions}

This paper has highlighted the effects of precast cladding systems typically used for Japanese steel buildings on the dynamic characteristics of steel frame structures. Dynamic tests on a full-scale one-story moment-resisting steel frame with the addition of ALC external wall cladding panels, gypsum plasterboard interior linings, and window glazing systems have been presented. Ambient vibration tests and free vibration tests were conducted to determine the fundamental characteristics of the test cases. The Random Decrement Technique and the Curve Fitting Technique were employed to estimate natural frequencies and damping ratios with respect to response amplitudes. The findings of the present study may be summarized as follows:

(1) Precast cladding systems provide a big increase in lateral stiffness over a bare steel frame that far outweighs the increase in mass. The increase in natural frequency of the bare steel frame due to the effect of ALC claddings could reach $40 \%$ at most, and the stiffness contributions from plasterboard and window glazing systems could increase the natural frequency of the bare steel frame by up to $10 \%$ separately.

(2) The addition of precast cladding systems to a bare steel frame greatly improves structural damping. The contributions of ALC cladding panels to structural 
TABLE 5: Comparison of dynamic parameters estimated from ambient and free vibration tests.

\begin{tabular}{|c|c|c|c|c|c|c|}
\hline \multirow{2}{*}{ Case } & \multicolumn{3}{|c|}{ Natural frequency } & \multicolumn{3}{|c|}{ Damping ratio } \\
\hline & $\operatorname{AVT}(\mathrm{Hz})$ & FVT (Hz) & AVT/FVT & $\operatorname{AVT}(\%)$ & FVT (\%) & AVT/FVT \\
\hline 1 & 3.40 & 3.41 & 1.00 & 0.1 & 0.20 & 0.50 \\
\hline 2 & 3.92 & 3.63 & 1.08 & 2.0 & 2.7 & 0.72 \\
\hline 3 & 4.07 & 3.77 & 1.08 & 1.9 & 2.4 & 0.78 \\
\hline 4 & 3.95 & 3.81 & 1.04 & 1.3 & 2.4 & 0.56 \\
\hline 5 & 4.42 & 4.16 & 1.06 & 1.5 & 2.4 & 0.63 \\
\hline 6 & 3.90 & 3.70 & 1.05 & 1.7 & 2.2 & 0.78 \\
\hline 7 & 4.27 & 3.95 & 1.08 & 0.9 & 2.2 & 0.43 \\
\hline 8 & 3.59 & 3.44 & 1.04 & 1.2 & 0.8 & 1.51 \\
\hline 9 & 3.76 & 3.53 & 1.07 & 1.3 & 1.0 & 1.27 \\
\hline 10 & 4.65 & 4.53 & 1.03 & 1.9 & 2.4 & 0.79 \\
\hline
\end{tabular}

damping lead to an increase in the damping ratio of a bare steel frame up to 18 -fold. However, plasterboard attached to ALC claddings restricts their rotational capacity, thus reducing the damping ratio. Window glazing systems also contribute to structural damping, and damping ratio decreases as window size increases.

(3) Amplitude dependency of dynamic characteristics develops with the existence of precast cladding systems. The dynamic parameters show nonlinearity with respect to response magnitude. Natural frequency tends to decrease with increasing amplitude, while damping ratio first increases but eventually decreases with increasing of response amplitude after reaching critical amplitude.

(4) The dynamic parameters derived from ambient vibration measurements are compared with those estimated from free vibration tests. It is found that natural frequencies estimated from ambient vibration tests are higher than those determined by free vibration tests, while damping ratios estimated from ambient vibration tests are generally lower than those determined by free vibration tests. These may be explained by the amplitude dependency of dynamic characteristics.

The findings in this study have some important implications for the design of steel frame structures in many parts of the world. While precast cladding systems are generally considered as nonstructural components in the design stage, interactions between precast cladding systems and primary structural members are inevitable, and the effect of precast cladding systems on dynamic characteristics should be taken into account; that is, the stiffness provided by precast cladding systems should be considered in determining the seismic loads on a structure, and amplitude-dependent damping ratio should be considered in predictions of structural dynamic responses. Hence, for accurate evaluation and design of steel frame buildings, it is essential to understand the effects of precast cladding systems on the dynamic characteristics of steel frame structures and to take account of these effects in the design stage.

\section{Conflicts of Interest}

The authors declare that they have no conflicts of interest.

\section{Acknowledgments}

The authors gratefully acknowledge the funding for this study provided by Asahi Kasei Homes Corporation Co., Ltd., the Ministry of Education, Culture, Sports, Science and Technology (MEXT), Japan, through the Global Center of Excellence (GCOE) Program, 2008-2012, and the China Scholarship Council (CSC).

\section{References}

[1] H. Palsson, B. J. Goodno, J. I. Craig, and K. M. Will, "Cladding influence on dynamics response of tall buildings," Earthquake Engineering \& Structural Dynamics, vol. 12, no. 2, pp. 215-228, 1984.

[2] F. A. Charney and J. R. Harris, "The effect of architectural precast concrete cladding on the lateral response of multistory buildings," in Proceedings of the Architectural Precast Concrete Cladding-Its Contribution to Lateral Resistance of Buildings, pp. 80-96, Chicago, Ill, USA, 1989.

[3] B. S. Smith and R. Gaiotti, "Interaction of precast concrete cladding with a story-height frame module," in Proceedings of the Architectural Precast Concrete Cladding-Its Contribution to Lateral Resistance of Buildings, pp. 48-61, Chicago, Ill, USA, 1989.

[4] R. Gaiotti and B. S. Smith, "Stiffening of moment-resisting frame by precast concrete cladding," PCI Journal, vol. 37, no. 5, pp. 80-92, 1992.

[5] J. P. Hunt and B. Stojadinovic, "Seismic performance assessment and probabilistic repair cost analysis of precast concrete cladding systems for multistory buildings," PEER Report, University of California, Oakland, Calif, USA, 2010.

[6] A. Baird, R. Diaferia, A. Palermo, and S. Pampanin, "Parametric investigation of seismic interaction between precast concrete cladding systems and moment resisting frames," in Proceedings of the Structures Congress, Las Vegas, Nev, USA, 2011.

[7] A. Colombo and G. Toniolo, "Problems of seismic design of the cladding panels of precast buildings," in Proceedings of the NZSEE Annual Technical Conference and AGM, Christchurch, New Zealand, 2012. 
[8] N. Uchida, T. Aoyagi, M. Kawamura, and K. Nakagawa, "Vibration test of steel frame having precast concrete panels," in Proceedings of the 5th World Conference on Earthquake Engineering, Rome, Italy, 1974.

[9] D. A. Foutch, S. C. Goel, and C. W. Roeder, Preliminary Report on Seismic Testing of a Full-Scale Six-Story Steel Building, Structural Research Series no. 527, Civil Engineering Studies, University of Illinois, Champaign, Ill, USA, 1986.

[10] S. S. Rihal, "Earthquake resistance and behavior of heavy facades/cladding and connections in medium-rise steel-framed buildings," in Proceedings of the 9th World Conference on Earthquake Engineering, Tokyo-Kyoto, Japan, 1988.

[11] N. Fukuwa, R. Nishizaka, S. Yagi, K. Tanaka, and Y. Tamura, "Field measurement of damping and natural frequency of an actual steel-framed building over a wide range of amplitudes," Journal of Wind Engineering and Industrial Aerodynamics, vol. 59, no. 2-3, pp. 325-347, 1996.

[12] A. Devin and P. J. Fanning, "Impact of nonstructural components on modal response and structural damping," in Proceedings of the 30th International Modal Analysis Conference, Jacksonville, Fla, USA, 2012.

[13] A. P. Jeary, "Damping in tall buildings-a mechanism and a predictor," Earthquake Engineering \& Structural Dynamics, vol. 14, no. 5, pp. 733-750, 1986.

[14] S. Lagomarsino, "Forecast models for damping and vibration periods of buildings," Journal of Wind Engineering and Industrial Aerodynamics, vol. 48, no. 2-3, pp. 221-239, 1993.

[15] Y. Tamura and S.-Y. Suganuma, "Evaluation of amplitudedependent damping and natural frequency of buildings during strong winds," Journal of Wind Engineering and Industrial Aerodynamics, vol. 59, no. 2-3, pp. 115-130, 1996.

[16] Q. S. Li, K. Yang, C. K. Wong, and A. P. Jeary, "The effect of amplitude-dependent damping on wind-induced vibrations of a super tall building," Journal of Wind Engineering and Industrial Aerodynamics, vol. 91, no. 9, pp. 1175-1198, 2003.

[17] A. Kasei, Hebel Technical Handbook, Asahi Kasei Construction Materials Corporation, Tokyo, Japan, 2014.

[18] C. J. Ku, Y. Tamura, A. Yoshida, J. Y. Kim, and D. Y. Kim, “Ambient vibration analysis of a spatial structure," in Proceedings of the 11th Americas Conference on Wind Engineering, San Juan, Puerto Rico, June 2009.

[19] F. Magalhães, E. Caetano, Á. Cunha, O. Flamand, and G. Grillaud, "Ambient and free vibration tests of the Millau Viaduct: evaluation of alternative processing strategies," Engineering Structures, vol. 45, pp. 372-384, 2012.

[20] R. Brincker, L. M. Zhang, and P. Andersen, "Modal identification from ambient responses using frequency domain decomposition," in Proceedings of the 18th International Operational Modal Analysis Conference, San Antonio, Tex, USA, 2000.

[21] D.-Y. Chiang, C.-S. Lin, and F.-H. Su, "Identification of modal parameters from ambient vibration data by modified eigensystem realization algorithm," Journal of Aeronautics, Astronautics and Aviation, Series A, vol. 42, no. 2, pp. 79-86, 2010.

[22] A. P. Jeary, "Establishing non-linear damping characteristics of structures from non-stationary response time-histories," The Structural Engineer, vol. 70, no. 4, pp. 61-66, 1992.

[23] A. G. Davenport and P. Hill-Carroll, "Damping in tall buildings: its variability and treatment in design," in Proceedings of the ASCE Spring Convention, Building Motion in Wind, Seattle, Wash, USA, 1986.
[24] K. Okada, Y. Nakamura, K. Shiba et al., "Forced vibration tests of ORC200 symbol tower, part 1 test methods and results," in Proceedings of the Summaries of Technical Papers of the Annual Meeting of Architectural Institute of Japan, Structures 1, pp. 875876, 1993 (Japanese).

[25] Y. Tamura, "Amplitude dependency of damping in buildings and critical tip drift ratio," International Journal of High-Rise Buildings, vol. 1, no. 1, pp. 1-13, 2012. 


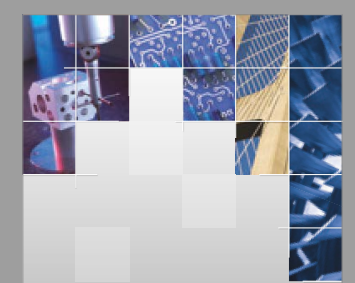

\section{Enfincering}
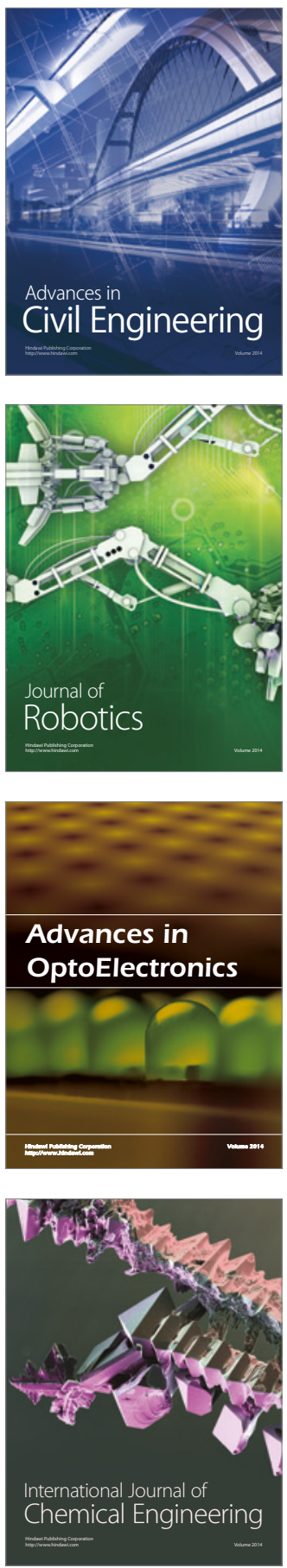

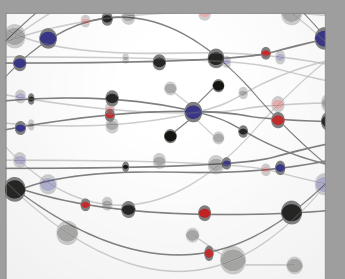

The Scientific World Journal

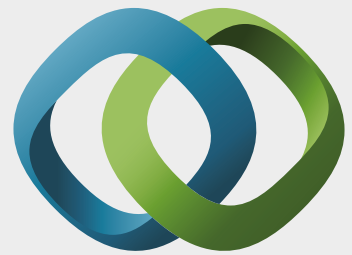

\section{Hindawi}

Submit your manuscripts at

https://www.hindawi.com
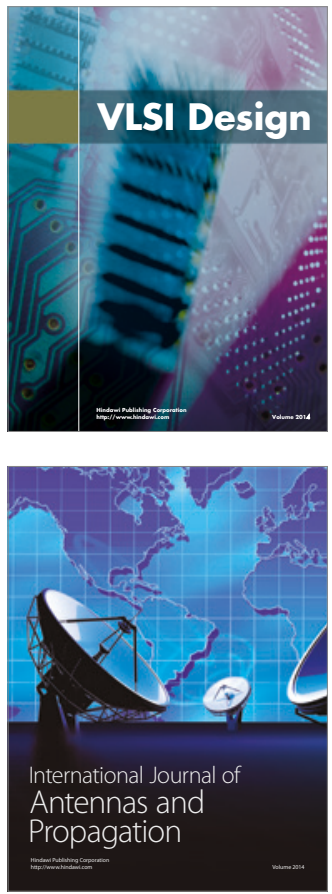

\section{Rotating}

Machinery
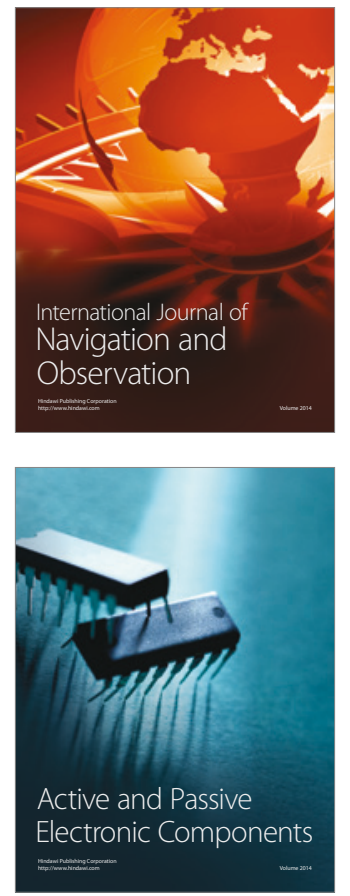
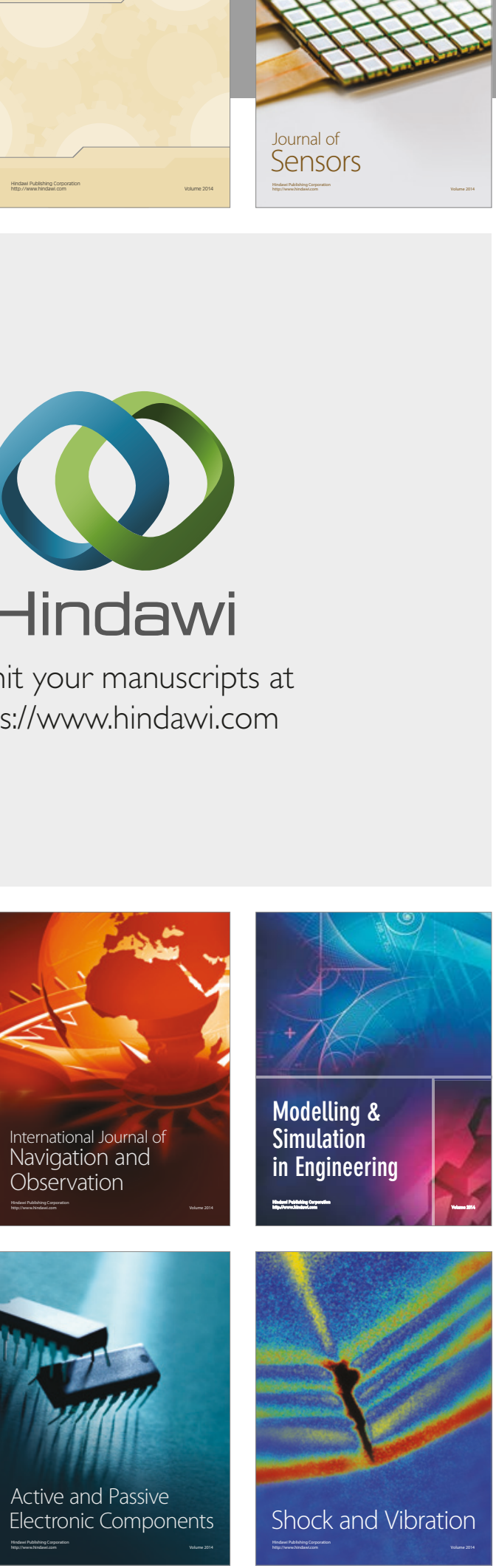
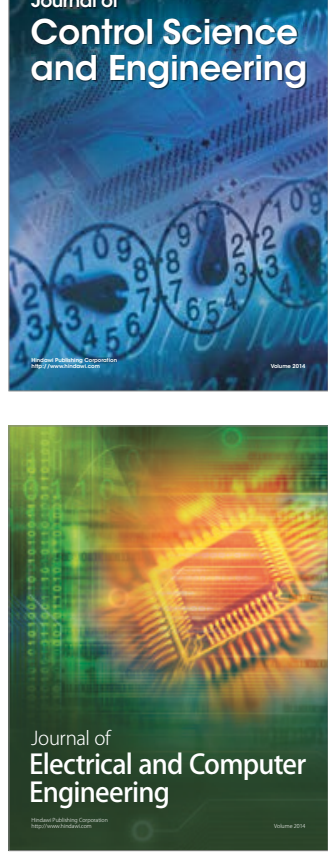

Distributed

Journal of

Control Science

and Engineering
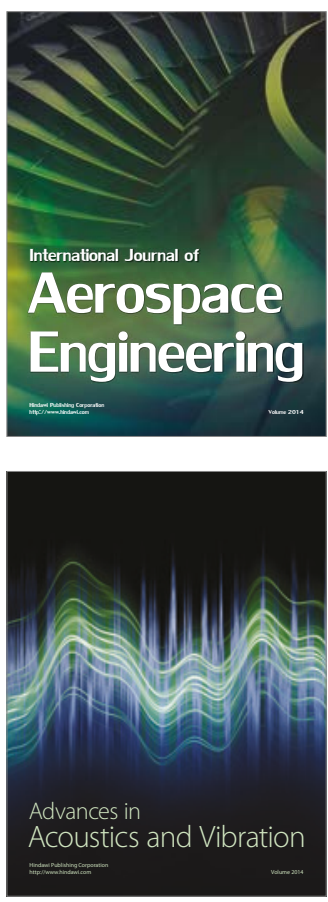

Sensor Networks 